\title{
A circuit-based approach to repair hypersexuality in Parkinson's disease
}

David Mata-Marín ${ }^{1,2,6 *}$, José Ángel Pineda-Pardo ${ }^{1,2 *}$, Mario Michiels ${ }^{1,2,6}$, Cristina Pagge $^{1,2,6}$, Claudia Ammann ${ }^{1,2}$, Raúl Martínez-Fernández ${ }^{1,2}$, José Antonio Molina ${ }^{3}$, Lydia Vela-Desojo ${ }^{4}$, Fernando Alonso-Frech ${ }^{5}$, Ignacio Obeso ${ }^{1,2}$

*Co-first authors

\section{Abstract}

One common neuropsychiatric complication in patients with Parkinson's disease treated with dopamine replacement therapy is impulse control disorders. A proportion of patients under dopamine agonist exhibit excessive desire towards appetitive cues accompanied by lost control over behaviour in forms of pathological gambling, hypersexuality or binge eating. The balance between enhanced desire towards sexual cues and cognitive control changes has been hypothesized to be biased toward the former in individuals with hypersexuality and impulse control disorders. Yet, some studies report no behavioural differences in cognitive control differences between impulsive patients and general Parkinson's disease, suggesting possible functional changes along the mesocorticolimbic cortico-subcortical circuitry. Here, we provide evidence for this hypothesis by comparing the neurobiological substrate of sexual disturbance over response inhibition associated to medication states in Parkinson's disease patients with a specific subtype of impulse control disorders (i.e., hypersexuality).

We assessed the impact of sexual cues on response inhibition using a novel erotic stop signal task inside an fMRI. A total of 50 participants were included divided in 16 hypersexual and 17 non-hypersexual Parkinson's disease patients and 17 healthy controls. Task-related activations, functional and anatomical connectivity models were performed. Additionally, a separate sample of 20 hypersexual Parkinson's disease patients received excitatory neuromodulation (sham-controlled) over the pre-supplementary motor area (based on fMRI group-based results) aiming to improve response inhibition when exposed to sexual cues.

Compared with their non-hypersexual peers, medication perturbed response inhibition upon presentation of sexual cues in patients with hypersexuality, recruiting a network NOTE: This preprint reports new research that has not been certified by peer review and should not be used to guide clinical practice. involving caudate, pre-supplementary motor area, ventral tegmental area, and anterior 
medRxiv preprint doi: https://doi.org/10.1101/2022.01.25.22269798; this version posted January $25,2022$. The copyright holder for this preprint (which was not certified by peer review) is the author/funder, who has granted medRxiv a license to display the preprint in It is made available under a CC-BY

perpetuity.

Hypersexuality alters cognitive control

cingulate cortex. Dynamic causal modelling revealed distinct best models to account for cortico-subcortical interactions with reduced task-related inputs in pre-supplementary motor area and descending connectivity to caudate in hypersexual compared to nonhypersexual Parkinson's disease patients (while medicated). This was sustained by enhanced fractional anisotropy and reduced mean diffusivity in the pre-supplementary motor area-caudate pathway. Importantly, stimulation over the pre-supplementary motor area improved response inhibition when exposed to sexual cues in hypersexual Parkinson's disease.

We identified a specific fronto-striatal and mesolimbic circuitry underlying uncontrolled sexual behaviours in Parkinson's disease induced by medication, with recovery options by applying neuromodulation.

\section{Author affiliations:}

1 HM CINAC. Centro Integral de Neurociencias AC. HM Puerta del Sur. HM Hospitales. Móstoles, Madrid, Spain.

2 Network Center for Biomedical Research on Neurodegenerative Diseases (CIBERNED), Instituto Carlos III, Madrid, Spain.

3 Hospital 12 de Octubre, Madrid, Spain.

4 Hospital Fundación Alcorcón, Madrid, Spain.

5 Hospital Clínico San Carlos, Madrid, Spain.

$6 \mathrm{PhD}$ program in Neuroscience, Autonoma de Madrid University, 28029 Madrid, Spain.

Correspondence to: Dr. Ignacio Obeso.

Avda. Carlos V, 70 Móstoles, 28938, Madrid, Spain.

iobeso.hmcinac@hmhospitales.com

www.controlandhabit.com

Running title: Hypersexuality alters cognitive control.

Keywords: hypersexuality; dopamine; impulse control disorders; fMRI; neuromodulation.

Abbreviations: $\mathrm{ACC}=$ anterior cingulate cortex; $\mathrm{fMRI}=$ functional magnetic resonance imaging; ICD = Impulse Control Disorder; PD $+\mathrm{HS}=$ Parkinson's disease and hypersexuality; PD-HS = Parkinson's disease without hypersexuality; pre-SMA = presupplementary motor area; $r T M S=$ repetitive transcranial magnetic stimulation; SSRT = stop signal reaction time; VTA = ventral tegmental area. 
medRxiv preprint doi: https://doi.org/10.1101/2022.01.25.22269798; this version posted January 25, 2022. The copyright holder for this preprint (which was not certified by peer review) is the author/funder, who has granted medRxiv a license to display the preprint in It is made available under a CC-BY-NCperpetuity.

Hypersexuality alters cognitive control

\section{Introduction}

2 Impulse control disorder (ICD) corresponds to one of the most acute and disturbing 3 neuropsychiatric complication in Parkinson's disease patients under dopaminergic 4 replacement therapy. The most prevalent forms include compulsive shopping, 5 pathological gambling, sexual behaviours or binge-eating amongst others, all marked by 6 the excessive tendency to compulsively engage in rewarding uncontrolled actions. ICDs are seen in about $17 \%$ of Parkinson's disease patients induced both by dopamine agonist and more rarely by levodopa $(6.9 \%)^{1-4}$. ICD sets patients at increased risk of financial ruin, family problems, prosecution, or job-related problems. Yet, its treatment follows two clinical routes: reducing dopaminergic doses at the expense of worsening movement output or invasive surgery. Hence, no specific treatments are available in ICD, prompting the available therapeutic windows to be consumed earlier than expected ${ }^{5}$.

It is commonly accepted that ICD is the result of a dopaminergic dysregulation of the mesolimbic pathway - including the orbital prefrontal cortex, anterior cingulate cortex (ACC), ventral striatum (nucleus accumbens), amygdala and ventral tegmental area (VTA) - that mediates reward. Mesolimbic dopaminergic dysregulation is thought to result from a hyperdopaminergic state caused by the action of dopaminergic therapy in the lesser denervated limbic striatum compared to more affected motor territories of the striatum $^{6}$. Indeed, the dopaminergic dysregulation changes reported in ICD along the mesolimbic pathway are similar to those seen in addiction pathophysiology $\mathrm{y}^{7,8}$. As a result, enhanced desire towards appetitive items occurs in ICD, driving excessive approach behaviours that find little or no opposition.

A dysregulated limbic system in Parkinson's disease and ICD sets excessive desire to primary and/or secondary rewards, possibly interfering with the neurocognitive signature needed to apply cognitive control operations. Indeed, Parkinson's disease and ICD patients reveal larger tendency for novelty seeking ${ }^{9}$ and enhanced incentive salience ${ }^{10,11}$, compatible with views on altered reward processing. Regarding cognitive control, Parkinson's disease and ICD modifies set-shifting abilities ${ }^{12-14}$ and impairs adaptation from negative outcomes ${ }^{15-17}$. Moreover, these impulsive patients show preference for smaller immediate rewards over larger and delayed ones ${ }^{18,19}$. Yet, we are uncertain whether a lack of cognitive control, enhanced desire or their imbalance is the basis of ICD associated to mesocorticolimbic regions. 
medRxiv preprint doi: https://doi.org/10.1101/2022.01.25.22269798; this version posted January 25, 2022. The copyright holder for this preprint (which was not certified by peer review) is the author/funder, who has granted medRxiv a license to display the preprint in It is made available under a CC-BY-NC-ND 4.0 International license .

Hypersexuality alters cognitive control

33 The "controlling brain network" in humans (namely inferior frontal gyrus, pre34 supplementary motor area (pre-SMA), striatum and the subthalamic nucleus ${ }^{20-24}$ is underactive in Parkinson's disease and ICD patients when making monetary choices, partly clarifying the clinical problem showing uncontrolled behaviour ${ }^{25,26}$. Yet, unaltered response inhibition in Parkinson's disease and ICD patients ${ }^{27,28}$ contrasts with altered engagement of the controlling network ${ }^{29,30}$ and increased engagement of the salience brain network responsible for switching between different brain neural dynamics ${ }^{31,32}$. Most studies include mixed ICD subtypes and evaluate behaviour with stimuli unrelated to their impulsive problem. Thus, to reduce the potential bias of unrelated stimuli with patient's impulsivity, the study of one predominant ICD using ad-hoc provocative stimuli will better pinpoint the specific circuits part of the clinical issue.

To this, we recruited Parkinson's disease patients with hypersexuality (PD+HS) and designed a novel paradigm combining erotic cues within a stop-signal task to investigate the behavioural, neural and connectivity (anatomical and functional) profile in PD+HS (study 1). Hypersexuality is one of the most common subtypes of ICD with an estimated prevalence of $13.6 \%$ in Parkinson's disease ${ }^{2}$. Hence, given response inhibition is vulnerable to high-arousal stimuli ${ }^{33,34}$, we hypothesized that sexual cues will bias response inhibition by altering fronto-striatal networks in hypersexual Parkinson's disease patients $(\mathrm{PD}+\mathrm{HS})$. Next, we hypothesized that response inhibition in PD+HS patients can be improved by means of repetitive transcranial magnetic stimulation (rTMS, study 2) - a non-invasive neuromodulation technique effective in improving response inhibition in the general and neuropsychiatric population ${ }^{35-37}$. Our design represents an advantage over prior studies as it counts with one ICD sub-type and assessed on response inhibition performance using ad hoc stimuli to provoke their symptomatology. The circuit-based approach hereby utilized may serve to elucidate the neurobiological changes when response inhibition is influenced by sexual desire in a specific subtype of ICD and use possible treatment options to offer novel therapies to a yet untreatable complication.

\section{Materials and methods}

\section{Participants}

Patients in both studies were heterosexual male and right-handed. In study 1, we included

6350 participants divided into 16 PD+HS patients, 17 non-hypersexual Parkinson's disease 
medRxiv preprint doi: https://doi.org/10.1101/2022.01.25.22269798; this version posted January 25, 2022. The copyright holder for this preprint (which was not certified by peer review) is the author/funder, who has granted medRxiv a license to display the preprint in It is made available under a CC-BY-NC perpetuity.

Hypersexuality alters cognitive control

64 patients (PD-HS) and 17 controls (Table 1). Study 2 included 20 PD+HS patients. Both

65 studies are consistent with sample sizes used in previous neuroimaging and stimulation studies in Parkinson's disease and ICD ${ }^{35,38}$. Patients met UK Brain Bank criteria for Parkinson's disease diagnosis. Due to the special recruitment criteria, 4 hospitals participated in the recruitment. Recruitment was confirmed after an initial interview with the neuropsychologist (with both patient and families) to confirm heterosexuality and hypersexuality ( $\geq 5$ on the sexual subscale of the Questionnaire for Impulsive-Compulsive Disorder in Parkinson's disease). The PD-HS group was selected based on absent or limited presence of ICD-related behaviours, while on-medication $(<4$ on the sexual subscale of the Questionnaire for Impulsive-Compulsive disorder in Parkinson's disease). Exclusion criteria were established based on presence of (i) cognitive dysfunction $(\leq 24$ on the Montreal Cognitive Assessment) (ii) depression (>18 in Beck Depression Inventory) or (iii) other severe comorbidities (e.g., history of substance abuse, homosexuality, hallucinations, or psychosis) detected during the interview. The study was approved by the Hospital Ethics Committee (17.03.0852E2-GHM).

\section{Procedure}

Patients were assessed while on and off-medication states (study 1, off-state defined as overnight dopaminergic drug withdrawal $\sim 12 \mathrm{hs}$ ) inside the functional MRI (fMRI) scanner with at least one week time between each session (order counterbalanced). Scores of internal arousal state were collected to obtain explicit measurements of sexual desire - by asking participants to mark between 0 (nothing) to 10 (very much) on how intense their internal state for pre-scanning was:

1. How much sexual appetite did you experienced in the last hour? 2. Did you feel increased libido in the last hour?

Similarly, after the fMRI session, in addition to the first 2 items above, the following items were included:

3. How much you felt nude images corrupted or slowed your responses? 4. How much you felt dressed images corrupted or slowed your responses?

Behavioural measures (classic stop signal task), neuropsychological, and neuropsychiatric tests were performed while on medication in both studies. 
medRxiv preprint doi: https://doi.org/10.1101/2022.01.25.22269798; this version posted January 25, 2022. The copyright holder for this preprint (which was not certified by peer review) is the author/funder, who has granted medRxiv a license to display the preprint in It is made available under a CC-BY-NC

Hypersexuality alters cognitive control

94 A single-blinded randomized controlled trial was designed to evaluate the acute effects

95 of rTMS (study 2). Each patient underwent both real and sham stimulation sessions in 96 separate two days maximum two-weeks apart (counterbalanced; on medication).

97 Following stimulation, patients performed the erotic stop-signal task described below.

\section{The erotic stop-signal task}

99 We designed an erotic stop-signal task using sexual cues (2 parallel versions; using a 100 previous database ${ }^{39}$ and additional images). Erotic and non-erotic images (added to 101 Prevost et $a l^{39}{ }^{39}$ ) were rated in a pre-experiment pilot phase, were healthy heterosexual 102 male participants $(n=22$; age (mean $\pm s d=48.4 \pm 2.5)$ rated valence and arousal states of the 103 new images. We selected the most consistent high-valued images to insert in the task 104 design. Images of undressed (erotic) and dressed women (non-erotic) were displayed 105 followed by left or right-pointing arrows (Figure 1A), where a left (index finger) or right 106 keypress (middle finger) with their dominant hand (limited time-hold up to 1s) was 107 required. On Stop trials (33\%), a stop signal cue was presented after a variable stop signal 108 delay (staircase procedure using 50ms steps) following go signals, asking patients to stop 109 their ongoing response. Null events ranged between 3-5s. Measures included response 110 initiation, stop signal reaction time (SSRT; integration method by replacing go omissions 111 with the maximum reaction time values per participant ${ }^{40}$, stop signal delay and proactive 112 action restraint as response delay effect (difference between erotic and non-erotic go 113 reaction times). Go trials above 3.5 standard deviation from the participant's mean 114 reaction time were discarded from the analysis. Twenty practice trials outside the scanner 115 were performed before each scanning session. A total of 384 trials (192 per image 116 condition) were performed per session, divided in five blocks of 77 trials per block.

117 Stimulus presentation and response recording were controlled using E-prime 2.0.

\section{Erotic stop-signal task analysis}

119 As recommended ${ }^{40}$, we first evaluated the independence of the go and stop processes by:

120 a) correlations between StopRespond reaction times and correct go trials of each stimuli 121 condition (erotic and non-erotic) per participant; b) correlations between the go trials and 122 SSRT; and c) plotting cumulative distributions of Go and StopRespond reaction times 123 (Figure 1C, 5A). 
medRxiv preprint doi: https://doi.org/10.1101/2022.01.25.22269798; this version posted January 25, 2022. The copyright holder for this preprint (which was not certified by peer review) is the author/funder, who has granted medRxiv a license to display the preprint in It is made available under a CC-BY perpetuity.

Hypersexuality alters cognitive control

\section{Behavioural, neuropsychological, and neuropsychiatric tests}

125 A classic stop signal task was used to obtain measures of response inhibition without

126 presence of sexual cues. General cognition and executive measures were included to

127 discard any cognitive downsides in our sample. To this, we employed the Montreal

128 Cognitive Assessment ${ }^{41}$ (as cognitive screening test), the Stroop interference test, Frontal

129 Assessment Battery, forward and backward digit span from Wechsler Adult Intelligence

130 Scale $\mathrm{IV}^{42}$ ), phonemic and semantic fluencies. Neuropsychiatric variables that may

131 influence ICDs were included (Barratt Impulsiveness Scale-11 ${ }^{43}$; Geriatric Depression

132 Scale ${ }^{44}$; Starkstein Apathy Scale ${ }^{45}$; Beck Anxiety Scale ${ }^{46}$ ). Last, a sexual inventory test

133 (Brief Male Sexual Function Inventory ${ }^{47}$ ) was used to include the latest sexual activities

134 in our sample.

135 Imaging data acquisition

136 Imaging data was collected using a 3T hybrid PET-MRI scanner (mMR Biograph, 137 Siemens AG, Germany) with a 12-channel head array coil. Task-based fMRI was 138 acquired using a single-shot gradient-echo echo-planar imaging (EPI) 2D pulse sequence 139 with the following parameters: $T R / T E=2000 / 30 \mathrm{~ms}$; optimum flip angle using the Ernst 140 equation i.e., $79^{\circ}$, spatial resolution $=3 \times 3 \times 4 \mathrm{~mm} 3$; field of view $=192 \mathrm{~mm}$; matrix $=$ $14164 \times 64$; slice thickness $=4 \mathrm{~mm}$ and acceleration factor of 2 (IPAT2). Five fMRI runs were 142 acquired per session (260 volumes per run, 12mins) with 2-min pause between runs. 143 Imaging protocol also included a 3D T1-weighted MP-RAGE $(T R / T E / T I=$ 144 2300/3.34/900ms; flip angle = 8; and isotropic spatial resolution $=1 \mathrm{~mm} 3$, FoV $=256 \mathrm{~mm}$, 145 matrix $=256 \times 256$, slice thickness $=1 \mathrm{~mm}$ ); a fieldmap generated from two 2D gradient146 echo images $\left(T R / T E 1 / T E 2=455 / 4.92 / 7.38 \mathrm{~ms}\right.$, flip angle $=60^{\circ}$ with the spatial resolution 147 as the fMRI EPI volumes); and diffusion weighted images (DWI) using a single-shot 2D 148 spin-echo EPI sequence $(T R / T E=10000 / 102 \mathrm{~ms}$; isotropic resolution $=2 \mathrm{~mm})$. DWI were 149 acquired for 64 non-collinear encoding directions with $b$-value $=1000 \mathrm{~s} / \mathrm{mm} 2$ and two $150 b=0 \mathrm{~s} / \mathrm{mm} 2$ images with opposite polarity of the phase encoding direction (AP and PA).

\section{1 fMRI preprocessing steps}

152 T1-weighted anatomical images for all subjects were segmented into gray matter, white 153 matter, and cerebrospinal fluid using the unified segmentation tool ${ }^{48}$ provided in SPM12. 154 Gray matter maps were then transformed into the Montreal Neurological Institute (MNI) 
medRxiv preprint doi: https://doi.org/10.1101/2022.01.25.22269798; this version posted January 25, 2022. The copyright holder for this preprint (which was not certified by peer review) is the author/funder, who has granted medRxiv a license to display the preprint in It is made available under a CC-BY-NC

Hypersexuality alters cognitive control

155 space using the DARTEL tool ${ }^{49}$. fMRI preprocessing was carried out with tools from FSL 156 (FMRIB Software Library) and SPM12. Preprocessing included slice timing correction, 157 motion correction by realigning to the first volume, correction of magnetic field 158 inhomogeneities induced geometrical distortions and signal dropout, and co-registration 159 to the anatomical images. Then, fMRI volumes were normalized to MNI space and 160 smoothed with an 8mm3 FWHM Gaussian kernel and filtered over time using a high161 pass filter of $128 \mathrm{~s}$. Omission errors and presses during sexual cues were classified as 162 errors for the fMRI analysis.

\section{Task-based fMRI analysis}

164 Task-related activities were analyzed by sexual cue types using the following regressors:

165 Go, Stop-Inhibit, Stop-Respond, Null, and motion regressors, derivatives and quadratic 166 forms, representing each event with an impulse function convolved with a canonical 167 hemodynamic response function. fMRI significance was considered at $p<.005$, with FWE 168 correction at the cluster level $(p<.05)$. Small-volume correction for anatomically defined 169 regions of interest were conducted in some regions based on a priori hypothesis.

\section{Dynamic causal modelling}

171 To extract regional time series for dynamic causal modelling, we specified an F test across 172 all trials $(F$ contrast: $p<.05)$ to obtain the first eigenvariate of the brain-oxygen-level 173 dependent imaging time series from 4 volumes of interest in Stop-Inhibit erotic vs. non174 erotic contrast: pre-SMA $[x=6, y=24, z=58]$, ACC $[x=0, y=24, z=36]$, caudate $[x=-10, y=8$, $175 z=14]$ and VTA [ $x=-4, y=-16, z=-14]$. Each subject's $F$ test was used to identify local 176 maxima closest to the group peak to then extract the first eigenvariate from a $5 \mathrm{~mm}$ sphere 177 at the subject-specific peak.

178 Dynamic causal modelling ${ }^{50}$ estimated the effective connectivity on 13 generative models 179 representing alternative hypotheses of the causal interactions between cortico-subcortical 180 areas guiding hypersexuality. Structural architecture of our models (Figure S1) was 181 informed by primate anatomical and human functional connectivity ${ }^{51-58}$. All models were 182 constructed, fitted, and compared for each patient (Supplementary Material). Bayesian 183 model selection ${ }^{59}$ was used to account for activity in the cortical and subcortical regions during the task and estimate the circuit abnormalities in hypersexuality ${ }^{59}$. Effective 
medRxiv preprint doi: https://doi.org/10.1101/2022.01.25.22269798; this version posted January 25, 2022. The copyright holder for this preprint (which was not certified by peer review) is the author/funder, who has granted medRxiv a license to display the preprint in It is made available under a CC-BY-NC.

Hypersexuality alters cognitive control

185 connectivity strength and task-modulations were compared with random-effects Bayesian

186 Model Averaging to obtain average connectivity estimates across models and patients ${ }^{59}$.

187 Diffusion Weighted Image Acquisition

188 After running whole brain diffusion tensor based tractography for each patient, the 189 corresponding tracts from the dynamic causal modelling model were segmented. 190 Preprocessing was performed using QSIPrep0.13.0RC1, which is based on Nipype $191 \quad 1.6 .0^{60,61}$.

\section{Diffusion Tensor Imaging Processing}

193 First, to ensure that diffusion tensor imaging was a viable model for this study, we inspected the different fibers directions for these tracts in the HCP1065 atlas and confirm they do not have a significant number of crossing fibers. Diffusion tensor estimation was carried out using the non-linear least-squares method implemented by Dipy. Spatial normalization in a tensor-based manner was done using dti-tk ${ }^{62}$. Then, tensors were normalized to a population template constructed by averaging each group of subjects. Finally, the images were mapped to $1 \mathrm{~mm}^{\wedge} 3 \mathrm{MNI}$ space. Relevant features - fractional anisotropy, mean diffusivity - were extracted at this point using dti-tk. Then we ran a deterministic tracking algorithm implemented in trackvis ${ }^{63}$, which resulted in a whole brain tractography per subject.

203 For tract selection across groups, we used automated fiber quantification ${ }^{64}$ to compute the

204 fractional anisotropy and mean diffusivity over the tracts, ensuring that the approximate 205 length and shape were similar between patients. A total of 100 nodes for fractional anisotropy values were obtained for each fibre bundle. To compute the difference between groups in fractional anisotropy and mean diffusivity, we conducted t-tests over the nodes for every tract (using TFCE as statistical method) between groups followed by non-parametric permutation tests ( $p<.05$, FWE Holm-Bonferroni corrections). This analysis was implemented using the code from ptsa ${ }^{65}$ and $\mathrm{MNE}^{66}$.

\section{Repetitive transcranial magnetic stimulation (rTMS)}

212 In study 2, we used rTMS (Magstim Rapid2 Plus1 stimulator, Magstim, Whitland, UK)

213 to apply intermittent theta burst stimulation ${ }^{67}$ over the pre-SMA $[x=6, y=24, z=58$; Stop-

214 Inhibit erotic vs non-erotic results in Study 1; Table 3], consisting of trains of 10 bursts 
medRxiv preprint doi: https://doi.org/10.1101/2022.01.25.22269798; this version posted January 25, 2022. The copyright holder for this preprint (which was not certified by peer review) is the author/funder, who has granted medRxiv a license to display the preprint in It is made available under a CC-BY-NC perpetuity. 4.0 International license.

Hypersexuality alters cognitive control

215 (2s) repeated every 10s for 20 cycles (600 pulses in total). Each burst consisted of a 3216 pulse burst $(50 \mathrm{~Hz})$ every $200 \mathrm{~ms}$ with $100 \%$ intensity relative to patient's dominant-hand 217 flexor digitorum. Scalp-to-cortex distance correction was used for intensity 218 adjustments $^{68}$. A T1-weigthed MRI scan of each patient was used to determine the exact 219 target location using Brainsight frameless stereotactic system (Rogue Research, Canada) 220 and a Polaris infrared (NorthernDigital, Canada). Sham stimulation was performed using 221 a sham-controlled coil (AirFilm Placebo, Magstim) controlling for device appearance and 222 physiological properties (i.e., sound) of stimulation.

\section{Statistical analysis}

224 Differences between conditions were analyzed using repeated-measures general linear 225 model comparing medication (on vs. off) and condition (erotic vs. non-erotic) as the 226 within groups variable and groups (PD+HS vs. PD-HS vs. controls) as between-group 227 variable for successful and unsuccessful stop trials. When comparing SSRT between 228 medication (on vs. off) and stimulation (real vs. sham), support for the alternative 229 hypothesis $(H-:$ SSRToff < SSRTon) vs the null hypothesis $(H 0:$ SSRToff $=$ SSRTon) 230 was also assessed with Bayesian paired t-tests (as implemented in JASP ${ }^{69}$, with default 231 effect size priors, Cauchy scale 0.707). Results are reported as one-tailed Bayes factor 232 (i.e., $B F_{-0} \quad$ represents $\mathrm{p}($ data| $\mid \mathrm{H}-) / \mathrm{p}($ data| $\mid \mathrm{H} 0)$. Moreover, correlations with 233 neuropsychological and clinical variables were executed with response inhibition 234 measures. Brain-behaviour Pearson correlations were executed between SSRT, and beta235 weights extracted from brain regions of interests, fractional anisotropy, and mean 236 diffusivity (mean values along the segments for each tract) and with effective connectivity 237 (dynamic causal modelling). Additional Pearson correlations between changes in SSRT 238 after rTMS and neuropsychological variables were calculated.

\section{Data availability}

240 Codes and data analysis pipelines can be found in https://github.com/cinac241 cognition/tms_fmri_dti_hypersexual_pd. Applications for de-identified anonymous data 242 can be made to HM-CINAC by contacting the corresponding author. Public access to the patient's data is not permitted following our local ethical restrictions. 
medRxiv preprint doi: https://doi.org/10.1101/2022.01.25.22269798; this version posted January 25, 2022. The copyright holder for this preprint (which was not certified by peer review) is the author/funder, who has granted medRxiv a license to display the preprint in

It is made available under a CC-BY-NC-ND 4.0 International license .

Hypersexuality alters cognitive control

244 Results

245 Clinical and demographics characteristics

Table 1. Demographic, clinical, and neuropsychological data for each group.

\begin{tabular}{|c|c|c|c|c|c|}
\hline & \multicolumn{3}{|c|}{ Study 1} & \multicolumn{2}{|r|}{ Study 2} \\
\hline & $\begin{array}{c}\text { PD+HS } \\
(n=14)\end{array}$ & $\begin{array}{l}\text { PD-HS } \\
(n=14)\end{array}$ & $\begin{array}{c}\text { Controls } \\
(n=16)\end{array}$ & Stats* & $\begin{array}{r}\text { PD+HS } \\
(n=18)\end{array}$ \\
\hline Age & $62.50 \pm 9.1$ & $65.40 \pm 5.4$ & $58.12 \pm 9.8$ & .96 & $57.89 \pm 8.0$ \\
\hline Education & $12.50 \pm 4.3$ & $12.93 \pm 3.9$ & $14.35 \pm 3.4$ & .69 & $12.71 \pm 2.9$ \\
\hline Disease duration & $8.38 \pm 3.2$ & $6.27 \pm 3.9$ & - & .14 & $6.89 \pm 4.5$ \\
\hline $\begin{array}{l}U P D R S-I I I^{\mathrm{a}} \\
(\mathrm{OFF})\end{array}$ & $29.31 \pm 7.4$ & $27.80 \pm 10.4$ & - & .41 & $28.65 \pm 11.4$ \\
\hline$U P D R S-I I I(\mathrm{ON})$ & $15.13 \pm 5.1$ & $14.53 \pm 6.2$ & - & .73 & $17.47 \pm 7.71$ \\
\hline$L E D D^{\mathrm{b}}($ total $)$ & $740.63 \pm 273.3$ & $549.29 \pm 293.2$ & - & .12 & $738.61 \pm 631.2$ \\
\hline$L E D D^{\mathrm{c}}(\mathrm{DA})$ & $206.67 \pm 84.3$ & $171.82 \pm 76.4$ & - & .44 & $362.67 \pm 74.3$ \\
\hline$L E D D^{\mathrm{d}}$ (L-dopa) & $583.33 \pm 237.3$ & $527.27 \pm 262.0$ & - & .52 & $375.94 \pm 286.8$ \\
\hline$Q U I P^{\mathrm{e}}$ total & $16.24 \pm 11.9$ & $5.27 \pm 8.5$ & $7.88 \pm 10.6$ & $<.01$ & $30.89 \pm 14.99$ \\
\hline Hypersexual & $6.41 \pm 3.9$ & $1.20 \pm 1.7$ & $1.47 \pm 1.8$ & $<.001$ & $8.61 \pm 3.78$ \\
\hline Gambling & $0.65 \pm 1.2$ & $0.20 \pm 0.5$ & $0.29 \pm 0.9$ & .21 & $1.00 \pm 2.17$ \\
\hline Shopping & $1.76 \pm 2.3$ & $0.67 \pm 1.4$ & $1.47 \pm 1.7$ & .12 & $3.83 \pm 4.45$ \\
\hline Binge eating & $2.76 \pm 3.3$ & $0.67 \pm 1.1$ & $1.46 \pm 1.9$ & .02 & $4.33 \pm 2.99$ \\
\hline Hobbyism & $1.35 \pm 2.2$ & $1.00 \pm 1.9$ & $1.65 \pm 2.3$ & .63 & $4.56 \pm 4.02$ \\
\hline Pounding & $1.24 \pm 2.3$ & $0.67 \pm 1.8$ & $1.47 \pm 2.3$ & .45 & $4.11 \pm 3.72$ \\
\hline Medication & $2.12 \pm 3.6$ & $0.87 \pm 1.7$ & $0.06 \pm 0.2$ & .23 & $4.44 \pm 4.08$ \\
\hline$M o C a^{\mathrm{f}}$ & $27.67 \pm 1.5$ & $28.00 \pm 1.3$ & $27.42 \pm 1.2$ & .41 & $27.94 \pm 2.1$ \\
\hline Stroop & $79.6 \pm 37.3$ & $62.6 \pm 14.5$ & $51.18 \pm 16.5$ & .10 & $57.89 \pm 8.1$ \\
\hline$F A B^{\mathrm{g}}$ & $17.33 \pm 0.9$ & $16.93 \pm 1.8$ & $17.94 \pm 0.2$ & .24 & $16.88 \pm 1.8$ \\
\hline$G D S^{\mathrm{h}}$ & $7.92 \pm 4.4$ & $8.77 \pm 6.1$ & $3.59 \pm 2.4$ & .59 & $8.18 \pm 7.1$ \\
\hline$B A I^{\mathrm{i}}$ & $11.85 \pm 5.0$ & $14.69 \pm 8.5$ & $6.94 \pm 4.3$ & .29 & $12.06 \pm 10.0$ \\
\hline$S A S^{\mathrm{j}}$ & $10.08 \pm 4.7$ & $12.15 \pm 8.8$ & $4.29 \pm 4.6$ & .46 & $11.94 \pm 6.4$ \\
\hline$B I S-I I I^{\mathrm{k}}$ & $79.50 \pm 18.5$ & $73.69 \pm 12.6$ & $81.08 \pm 12.8$ & .39 & $58.44 \pm 8.4$ \\
\hline$B S F I^{1}$ & $26.82 \pm 10.2$ & $21.00 \pm 7.1$ & $23.75 \pm 12.5$ & .11 & $12.71 \pm 2.9$ \\
\hline
\end{tabular}

Stats: unpaired t-test between PD+HS and PD-HS; between groups; ${ }^{\text {a}} U P D R S-I I I$ : Unified Parkinson's Disease Rating Scale; ${ }^{\mathrm{b}} L E D D$ : Levodopa Equivalent Daily Dose (total mg). ${ }^{\mathrm{c}} L E D D-D A$ : Levodopa Equivalent Daily Dose of Dopamine Agonist (total DA $\mathrm{mg}$ ); ${ }^{\mathrm{d}} L E D D$-L-dopa: Levodopa Equivalent Daily Dose (total Levodopa mg); ${ }^{\circ} Q U I P$ : Questionnaire for Impulsive-Compulsive; ${ }^{\mathrm{f}} \mathrm{MoCa}$ : Montreal Cognitive Assessment; ${ }^{\mathrm{g}} \mathrm{FAB}$ : Frontal Assessment Battery; ${ }^{\mathrm{h}} \mathrm{GDS}$ : Geriatric Depression Scale; ${ }^{\mathrm{i}} B A I$ : Beck's Anxiety Inventory; ${ }^{\mathrm{S}} S A S$ : Starkstein Apathy Scale; Disorders in Parkinson's; ${ }^{\mathrm{k}} B I S$-III: Barratt Impulsiveness Scale; ${ }^{1} B S F I$ : Brief Sexual Function Inventory.

246 Groups were matched in terms of age, education, and clinical variables. While PD+HS 247 patients also experienced other ICD subtypes in addition to hypersexuality (Table 1), it 248 was the most dominant ICD subtype according to the initial interview (patient and 249 families) and scores on the Questionnaire for Impulsive-Compulsive Disorder in 250 Parkinson's disease. Binge eating was the $2^{\text {nd }}$ most frequent subtype in our sample.

251 Evaluation of sexual arousal before and after task performance was collected to ensure 252 the observed behaviour and fMRI signals were based on a real sexual change (Table 2). 253 A total sample size of 14 PD+HS, 14 PD-HS and 16 controls were included in the final 254 analysis (study 1). Excluded patients were due to significant reductions in their 
medRxiv preprint doi: https://doi.org/10.1101/2022.01.25.22269798; this version posted January 25, 2022. The copyright holder for this preprint (which was not certified by peer review) is the author/funder, who has granted medRxiv a license to display the preprint in It is made available under a CC-BY-NC perpetuity. 4.0 International license.

Hypersexuality alters cognitive control

255 hypersexuality between scanning sessions ( $n=2$ PD+HS patients) and motion artifacts

256 ( $n=3$ PD-HS patients; $n=1$ control). Secondly, a total of 18 PD+HS patients were included

257 in the final analysis (study 2) as reduced hypersexuality between neuromodulation

258 sessions was seen $(n=2)$. As part of the recruitment process (not included in the initial 259 sample size), two-step interviews rejected $n=7$ patients ( $n=1$ depressed patient, $n=1$

260 unwilling to spend time in the scanner, $n=3$ had cognitive deficits, $n=2$ homosexual 261 patients).

262 Behavioural results

Table 2. Sexual desire pre- vs. post-task performance and exposure to sexual visual stimuli.

\begin{tabular}{cccc} 
& pre-task & post-task & $p$-values \\
\hline Off session & & & \\
$P D+H S$ & $2.76 \pm 1.1$ & $4.43 \pm 1.3$ & $<.001^{\mathrm{a}}$ \\
$P D$ - $H S$ & $0.90 \pm 0.6$ & $1.10 \pm 0.7$ & $.18^{\mathrm{a}}$ \\
$p$-values & $<.001^{\mathrm{b}}$ & $<.001^{\mathrm{b}}$ & \\
On session & & & \\
$P D+H S$ & $2.74 \pm 0.9$ & $5.65 \pm 1.0$ & $<.001^{\mathrm{a}}$ \\
$P D$ - $H S$ & $0.60 \pm 0.5$ & $0.90 \pm 0.5$ & $.09^{\mathrm{a}}$ \\
$p$-values & $<.001^{\mathrm{b}}$ & $<.001^{\mathrm{b}}$ & \\
\hline Results obtained from average values of first two items on the arousal scale ${ }^{\mathrm{a}}$ Paired t-test comparison: ${ }^{\mathrm{b}}$ unpaired t-test comparison
\end{tabular}

263 Our ad-hoc behavioural task generated enhanced arousal in PD+HS patients while on264 medication (Table 2). Under the race stopping model, going and stopping are supposed 265 to act independently ${ }^{70}$, confirmed in our data following recommended tests ${ }^{40}$, such as 266 faster StopRespond reaction times compared to go trials (Figure 1C; Supplementary 267 Material). Group and medication effects modulated differently response inhibition 268 [Table S1; Figure 1B; medication x group, $F(2,44)=5.92, p=.006$; group, $F(2,44)=7.07$, $269 p=.002]$, where post-hoc tests showed significant medication effects in PD+HS $[t(12)=-$ $2703.06, p=.01]$ with strong evidence that response inhibition was impaired by medication 271 and sexual cues $\left[B F_{-0}=11.60\right.$; see sequential analysis in Figure S2]. Performance before 272 medication (off medication) explained improved SSRT in PD+HS (positive correlations 273 between SSRT on-off medication difference and on medication; $r=.753, p=.003$; Figure 274 1E). Proactive response delay effects were modulated by group $[F(1,44)=4.11, p=.02]$, 275 explained by increased response adaptation in controls compared to PD+HS (on 276 medication, $\mathrm{p}=.02$ ) and PD-HS patients (on medication, $p=.01$; Figure 1D) and by 277 medication $[F(1,44)=4.52, p=.04]$, as evident from faster adaptation while on medication 278 in PD+HS $[p<.03$; Figure 1D]. As expected, classic measures of response inhibition 
medRxiv preprint doi: https://doi.org/10.1101/2022.01.25.22269798; this version posted January 25, 2022. The copyright holder for this preprint (which was not certified by peer review) is the author/funder, who has granted medRxiv a license to display the preprint in It is made available under a CC-BY-NC

Hypersexuality alters cognitive control

279 (without erotic cues) revealed no impairments in PD+HS compared to controls

280 (Supplementary Material).

281 Figure 1. Behavioural paradigm and results. SSRT estimates as a function of

282 Group and Medication conditions in Study 1.

A

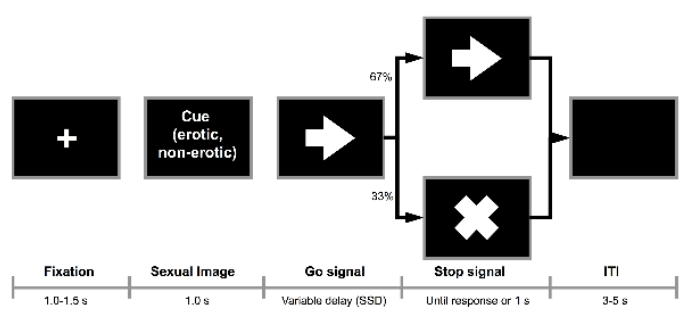

B $\mathrm{PD}+\mathrm{HS} \bigcirc \mathrm{PD}-\mathrm{HS}$ Controls
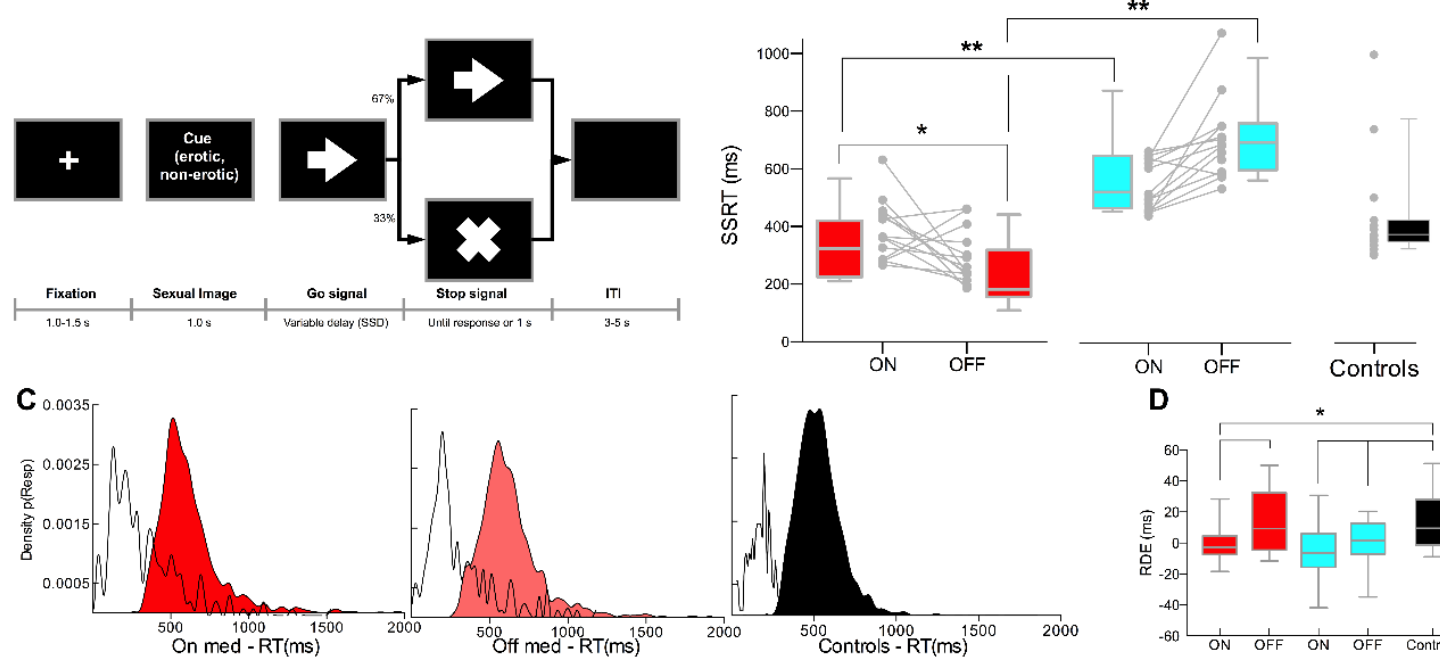

On med - RT(ms)
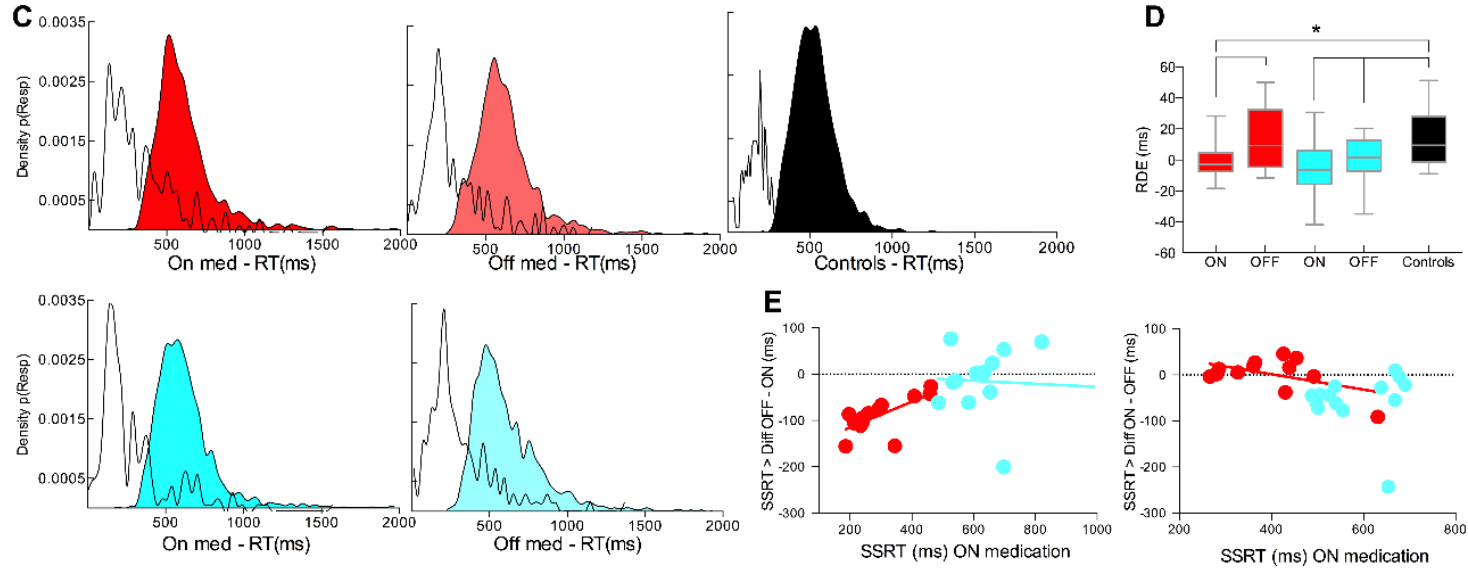

Study 1 (A) Task trial example; (B) SSRT for groups and individual dots per group and medication states; (C) Density distribution for StopRespond and Go conditions; (D) Response delay effect (RDE) between erotic and non-erotic go trials; (E) Within-subject change in SSRT from off to on levodopa medication is illustrated with single dots correlations showing greater benefits in response inhibition (i.e., reduction in SSRT from "off" to "on" status). *p<.05; ** $p<.01$. Results are shown as box-and-whisker plots with each

\section{fMRI results}

\section{Neural Network for inhibition under erotic influence}

To decipher the key areas behind successful inhibition (Stop-Inhibit) under sexual influence, a general linear model on group, condition and medication revealed a medication by group interaction and medication effect over superior parietal lobe activity (Table 3; Figure 2A). This effect was driven by the PD+HS group also significantly recruiting the ACC, middle frontal gyrus, caudate and VTA (Table 3; Figure 2B). Meanwhile, a group effect showed increased activity over the pre-SMA in the PD+HS compared to PD-HS group (on medication; Table 3; Figure 2C). Moreover, successful 
medRxiv preprint doi: https://doi.org/10.1101/2022.01.25.22269798; this version posted January 25, 2022. The copyright holder for this preprint (which was not certified by peer review) is the author/funder, who has granted medRxiv a license to display the preprint in

It is made available under a CC-BY-NC-ND 4.0 International license .

Hypersexuality alters cognitive control

297 inhibition of actions (compared to unsuccessful inhibition) revealed a main effect of

298 medication over superior parietal lobe, ACC, and supplementary motor complex (Table

299 S3; Figure S3A). This effect was mediated by the PD+HS group (on vs off medication)

300 showing enhanced activity in frontal pole, supplementary motor area and inferior frontal

301 gyrus (Table S3; Figure S3B).

Table 3. Stop-Inhibit in Erotic vs. Non-Erotic trials.

\begin{tabular}{|c|c|c|c|c|c|}
\hline & T-value & $\mathbf{X}$ & $\mathbf{Y}$ & $\mathbf{Z}$ & Stats \\
\hline \multicolumn{6}{|l|}{ Medication } \\
\hline \multirow[t]{3}{*}{ Superior parietal lobe } & 4.02 & -62 & -8 & -14 & $*$ \\
\hline & 3.29 & -56 & 4 & -18 & $*$ \\
\hline & 3.89 & -52 & -20 & 54 & $*$ \\
\hline \multicolumn{6}{|l|}{$P D+H S$ on $>$ off } \\
\hline Superior parietal lobe & 4.04 & -34 & -6 & 64 & $* *$ \\
\hline Middle frontal gyrus & 3.67 & -14 & 28 & 58 & $* *$ \\
\hline \multirow[t]{2}{*}{ Anterior cingulate cortex (dorsal) } & 3.62 & 10 & 26 & 46 & $* *$ \\
\hline & 3.53 & 4 & 28 & 20 & $*$ \\
\hline \multirow[t]{2}{*}{ Caudate } & 3.50 & -6 & 8 & 16 & $*$ \\
\hline & 3.36 & -14 & 2 & 14 & $*$ \\
\hline Ventral tegmental area (VTA) & 3.37 & -2 & -16 & -12 & $* \wedge$ \\
\hline \multicolumn{6}{|l|}{$P D+H S>P D-H S$ on } \\
\hline \multirow[t]{3}{*}{ Superior parietal lobe } & 4.35 & -52 & -20 & 54 & $* *$ \\
\hline & 3.91 & -36 & 2 & 60 & $* *$ \\
\hline & 3.84 & -42 & -26 & 46 & $* *$ \\
\hline \multirow{4}{*}{$\begin{array}{l}\text { Pre-supplementary motor area } \\
\text { (Pre-SMA) }\end{array}$} & & & & & $* *$ \\
\hline & 3.77 & 6 & 24 & 58 & \\
\hline & 3.73 & -14 & 30 & 58 & $* *$ \\
\hline & 3.66 & -24 & 22 & 56 & $* *$ \\
\hline
\end{tabular}

Tests and anatomical structures for the successful (stop-inhibit) in erotic vs. non-erotic trials. $p<.05$ FWE cluster-wise corrected; $* p<.005 ; * * p<.001$.

302 Figure 2. Neural correlates for successful inhibition in erotic vs non-erotic 303 conditions.

A $\mathrm{PD}+\mathrm{HS} \bigcirc \mathrm{PD}-\mathrm{HS}$

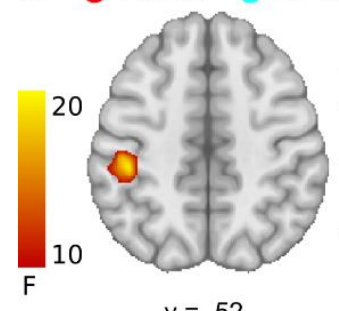

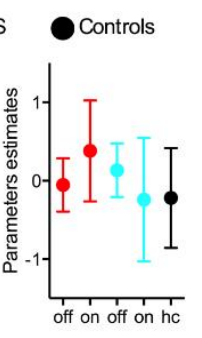

B

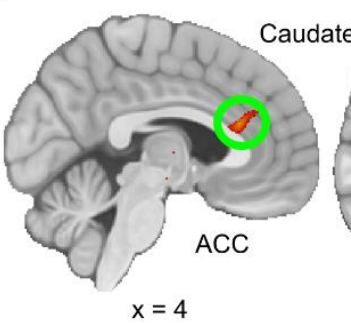

C

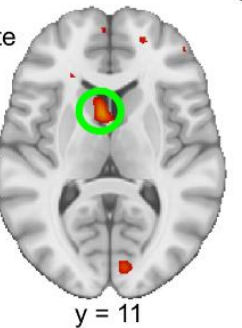

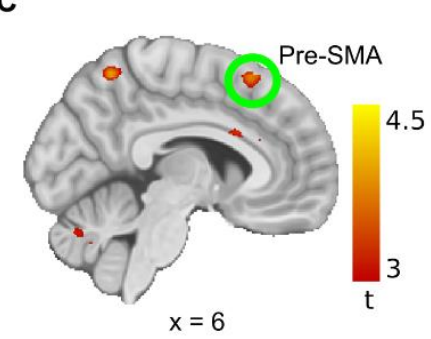

(A) Medication x Group interaction with parameter estimates over superior parietal cortex per group; (B) Medication effect revealing increased activity in PD+HS comparing on vs. off medication states; (C) Group effect revealing enhanced activity in the PD+HS 
medRxiv preprint doi: https://doi.org/10.1101/2022.01.25.22269798; this version posted January 25, 2022. The copyright holder for this preprint (which was not certified by peer review) is the author/funder, who has granted medRxiv a license to display the preprint in It is made available under a CC-BY-NC. perpetuity.

Hypersexuality alters cognitive control

308 Neural correlates of successful and unsuccessful inhibition under erotic influence

309 Following sexual cues, successful (Stop-Inhibit) compared to unsuccessful inhibition

310 showed a disease $\mathrm{x}$ medication interaction as well as in medication effects in the

311 postcentral gyrus over the parietal cortex (Table S4). Post-hoc tests showed significant

312 activity increase in the PD+HS group (compared to PD-HS group while medicated) in the

313 precuneus and supplementary motor area as well as the superior parietal lobe (Table S4).

314 In contrast, when looking at the specific activity patterns in unsuccessful inhibition for

315 the erotic (against non-erotic trials), we observed a disease $\mathrm{x}$ medication interaction over

316 the ACC (Table S5). This activity was guided by the PD-HS group, which showed

317 significantly higher activity than PD+HS patients in the ACC while medicated (Table

318 S5).

319 Unsuccessful inhibition under erotic influence

320 Given hypersexuality may be driven by failure to control ongoing behaviour when

321 exposed to sexual cues, we analysed the erotic influence over failed inhibition at the

322 neural level. Failing to stop specifically under erotic influence (erotic vs. non-erotic trials)

323 revealed a significant medication $\mathrm{x}$ group interaction over the superior parietal lobe,

324 supplementary motor area and superior frontal gyrus (Table S5). Such interaction

325 revealed in PD+HS patients (on vs. off) a significant cluster activity over the left caudate

326 ( $p<.005$, small volume correction FWE corrected; Table S5), a region that is also present

327 during Stop-Inhibit in erotic trials.

328 Cortico-subcortical influences underlying response inhibition

329 The cortico-subcortical model comparison revealed striking results: there was strong

330 evidence in favour of one model above all others (model 12; Figure 3B). Across groups,

331 the pre-SMA to both caudate and ACC connections were excitatory (Figure 3A).

332 Importantly, significant differences in pre-SMA-caudate connectivity were seen between

333 PD+HS $(0.004 \pm 0.006)$ and PD-HS patients $(0.02 \pm 0.03)$ while medicated $(p=.02$; Figure

334 3C). Moreover, pre-SMA-caudate connectivity was modified by medication in PD+HS

335 (on vs. off: $p=.03$; Figure 3C). Local intrinsic connectivity in the caudate correlated with

336 SSRT in PD+HS patients while medicated $(r=.55, p=.04)$, which reflects local neuronal

337 adaptation, suggesting an altered neurobiological link to response inhibition changes. 
medRxiv preprint doi: https://doi.org/10.1101/2022.01.25.22269798; this version posted January 25, 2022. The copyright holder for this preprint (which was not certified by peer review) is the author/funder, who has granted medRxiv a license to display the preprint in

It is made available under a CC-BY-NC-ND 4.0 International license .

Hypersexuality alters cognitive control

Figure 3. Dynamic causal modelling (DCM), winning model and group differences.

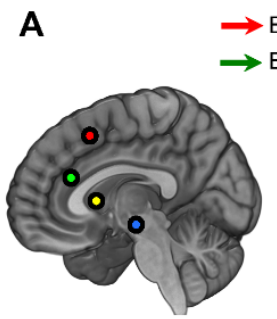

$\rightarrow$ Erotic image

Erotic Stop-Inhibit

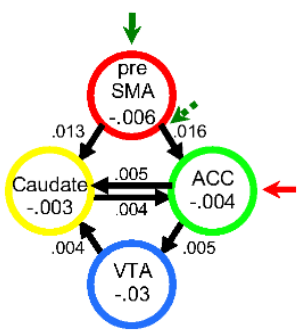

C
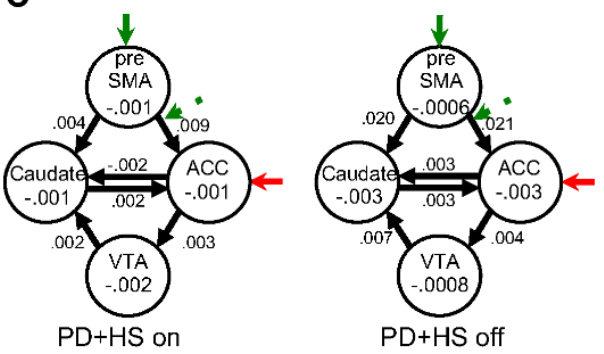

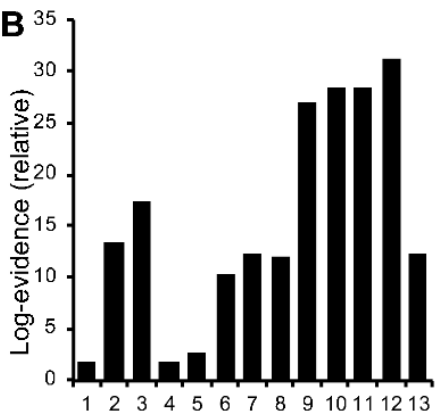

Models

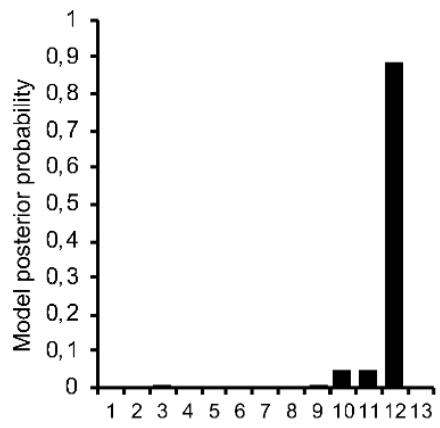

Models

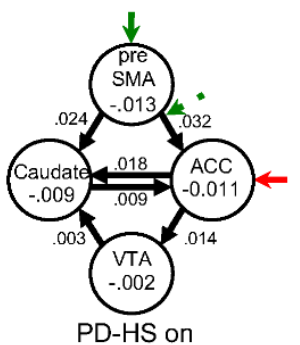

PD-HS on

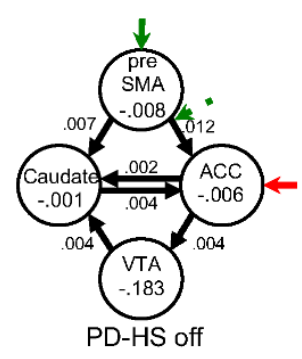

PD-HS off

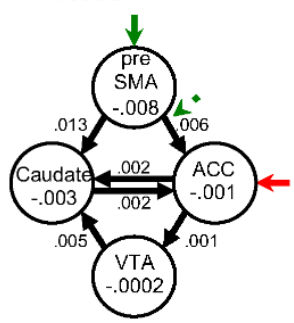

Controls

340 (A) Bayesian Model Selection (BMS): dotted arrows indicate modulatory effects of stopping (correct stop-inhibit) and erotic cues. Solid bold arrows indicate driving inputs of task performance locally. Models share local effects of task on pre-SMA structure. The most likely model counts with increased excitatory connectivity from the pre-SMA to the caudate and ACC (DCM.A average connectivity). This connectivity is modulated locally in pre-SMA by task (DCM.B) and by modulatory inputs in descending connection towards ACC (DCM.A). Bidirectional connections between ACC and caudate are detected (DCM.A); (B) Using the freeenergy estimate of the log-model evidence between models, very strong evidence was found in favor of one model (Figure 3A). The group posterior probability (close to 1) illustrates the strong support for the most likely model; (C) Model connectivity values after Bayesian parameter averaging at the group level reveal reduced excitatory connectivity in pre-SMA to caudate pathway between PD+HS and PD-HS patients. Ultimately, local task modulation over pre-SMA differed between patients.

\section{Local modulatory effects of Stop-Inhibit}

The winning effective connectivity model revealed a task modulation (Stop-inhibit in erotic vs non-erotic) over pre-SMA, significantly different between PD+HS $(0.04 \pm 0.11)$ and PD-HS groups (-.10 $\pm 0.16 ; p=.01$; Figure 3C). This finding is indicative of local preSMA differential responses to stop cues between patients may contribute descending aberrant signals to control behaviour.

\section{Structural connectivity}

We observed bilateral significant differences in the pre-SMA-caudate tract, showing higher fractional anisotropy values and lower mean diffusivity (Figure 4B) in PD+HS compared to PD-HS group and controls (Figure S4). Interestingly, the opposite pattern is seen for the caudate-ACC tract with lower fractional anisotropy but also reduced mean diffusivity values in PD+HS compared to PD-HS patients; Figure 4C). The VTA-caudate 
medRxiv preprint doi: https://doi.org/10.1101/2022.01.25.22269798; this version posted January 25, 2022. The copyright holder for this preprint (which was not certified by peer review) is the author/funder, who has granted medRxiv a license to display the preprint in It is made available under a CC-BY-NC perpetuity. 4.0 International license.

Hypersexuality alters cognitive control

361 tract could not be robustly reconstructed with the diffusion tensor imaging model and the 362 proposed tractography algorithm, thus excluded from the analysis. Along the right pre-

363 SMA-caudate tract, mean diffusivity values showed a positive SSRT correlation for PD-

364 HS patients $(r=.79, p=.01$; Figure S5) but a non-significant negative correlation in 365 PD+HS (off medicated, $r=-.20 ; p=.61$; Figure S5). Thus, structural connectivity predicted 366 behavioural changes between patients' groups.

367 Figure 4. Tracts representation and diffusion tensor imaging (DTI) scalar measures - fractional anisotropy $(F A)$, mean diffusivity $\left(M D^{*}\right)$.
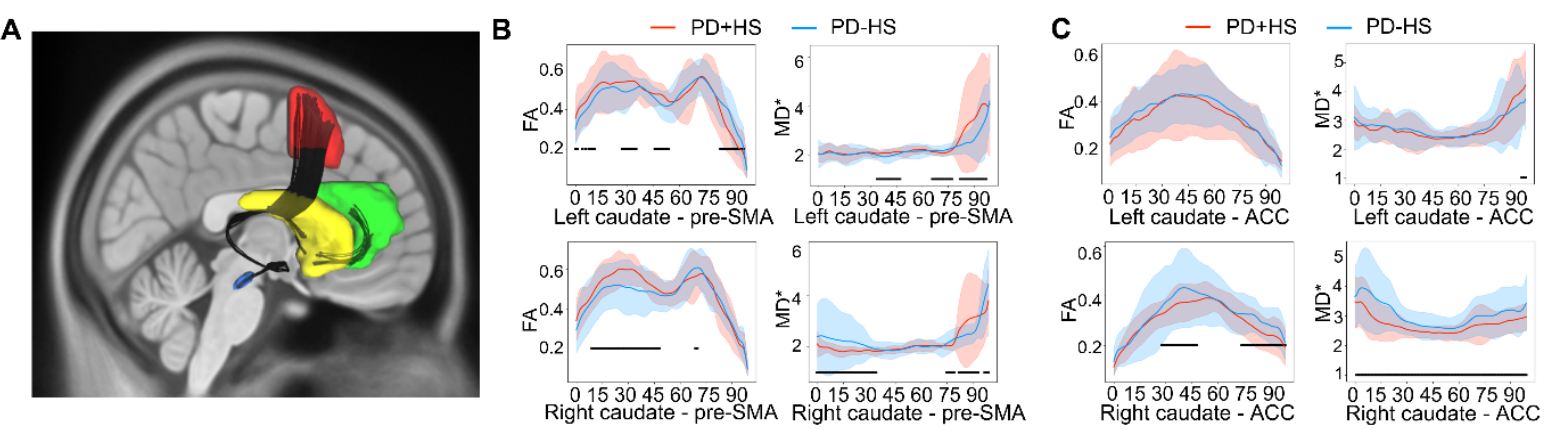

Comparisons included PD+HS ( $n=10)$ and PD-HS patients $(n=14)$ and controls $(n=13)$; (A) Tracts segmentation between areas in the dynamic causal modelling (DCM; VTA, caudate, ACC, pre-SMA) in the HCP1065 template, superposed on a T1 MNI template; (B); (C) FA and $M D$ along the segments of each tract. Significant differences ( $p<.05$ corrected) along the segments between the groups are underlined in black (see Supplementary Material for more details about the thresholding procedure).

\section{Structural connectivity predicts effective connectivity}

We tested fractional anisotropy and mean diffusivity correlations with dynamic causal modelling parameters in cortico-subcortical tracts. A relevant approaching significance negative correlation was found between fractional anisotropy and dynamic causal modelling from the right pre-SMA and caudate connection in PD+HS patients $(r=-.69$, $p=.06)$. Thus, higher fractional anisotropy in $\mathrm{PD}+\mathrm{HS}$ patients corresponds to lower effective connectivity (Figure S6), consistent with pathological compensatory responses to preserve functional connectivity ${ }^{71,72}$.

\section{Non-invasive brain stimulation: repairing hypersexual behaviour}

Following real intermittent theta burst stimulation over the pre-SMA (compared to sham), significant improvement of response inhibition was found in PD+HS patients for erotic $(p=.02)$ and non-erotic $(p=.04)$ stimuli (Figure 5B), an effect showing moderate evidence towards the alternative hypothesis $[B F-0=3.40$; sequential analysis in Figure S7]. Moreover, faster Go reaction times in both erotic $(p=.06)$ and non-erotic $(p=.04)$ stimuli 
medRxiv preprint doi: https://doi.org/10.1101/2022.01.25.22269798; this version posted January 25, 2022. The copyright holder for this preprint (which was not certified by peer review) is the author/funder, who has granted medRxiv a license to display the preprint in It is made available under a perpetuity. perpetuity.
CC-BY-NC-ND 4.0 International license .

Hypersexuality alters cognitive control

388

were seen across patients (Figure 5C). Independence race-model assumptions were also confirmed in this study (Figure 5A; Supplementary Material). Correlation analysis between response inhibition and backwards digit span correlated with larger improvements in SSRT after intermittent theta burst stimulation $(r=.49 ; p=.03)$. Finally, results were not affected by possible session order effects (Supplementary Material).

Figure 5. Neuromodulation effects on cognitive control and hypersexuality. Study 2.

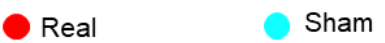

A
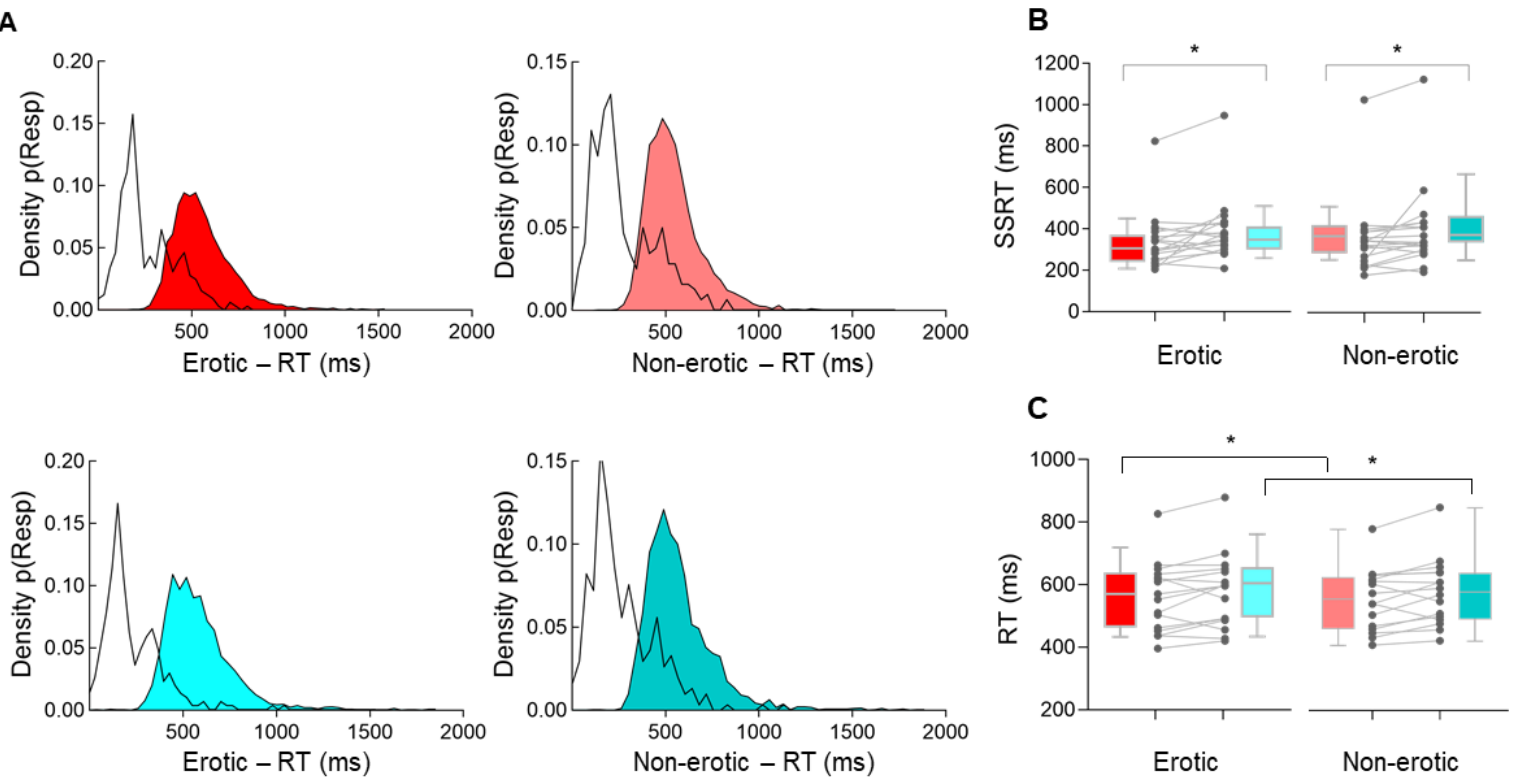

(A) Density distribution for StopRespond (white distribution) and Go trials (coloured) per stimulation session and per trial type; (B) Boxplot and individual values for SSRT and (C) Go trials reaction times for erotic and non-erotic trials after real and placebo stimulations. ${ }^{*} p<.05$; Results are shown as box-and-whisker plots with each box representing the 10-90 percentile where medians are represented by internal lines.

\section{Discussion}

399 Impaired response inhibition was found in PD+HS when exposed to sexual cues while on

400 medication. The cortico-striatal regions responsible for uncontrolled sexual behaviours

401 included inhibitory hubs such as the pre-SMA, but also the VTA, caudate and ACC as

402 part of the limbic system. Effective connectivity models revealed less engagement of pre-

403 SMA in stop-related trials and reduced functional connectivity with the caudate in

404 PD+HS compared to PD-HS patients, showing opposite SSRT correlations between

405 patients. This functional change was held by enhanced fractional anisotropy and reduced

406 mean diffusivity in the pre-SMA-caudate pathway in PD+HS. Importantly, excitatory

407 neuromodulation over the pre-SMA improved response inhibition under sexual influence

408 in PD+HS patients. Our results provide compelling evidence to understand the 
medRxiv preprint doi: https://doi.org/10.1101/2022.01.25.22269798; this version posted January 25, 2022. The copyright holder for this preprint (which was not certified by peer review) is the author/funder, who has granted medRxiv a license to display the preprint in It is made available under a CC-BY-NC

Hypersexuality alters cognitive control

409 neurobiological underpinnings of hypersexual behaviour and reveal, to the best of our

410 knowledge, a first attempt using non-invasive neuromodulation to repair hypersexuality

411 in Parkinson's disease.

\section{Sexual cues impair response inhibition in PD+HS patients}

413 We observed greater disruption of response inhibition upon presence of sexual cues

414 driven by dopaminergic medication (Figure 1B). Moreover, proactive control between

415 conditions was reduced while on medication (Figure 1D), suggesting some form of

416 anticipatory maladaptation in PD+HS. In other words, dopaminergic drugs impaired

417 controlling systems needed to respond upon sexual signals, since PD+HS patients showed

418 no impairments in response inhibition in a classic stop signal task. Hence, our results add

419 notions of updated behavioural methods (ad-hoc stimuli related to the clinical problem)

420 to test cognitive disturbances and help solving current debates on why some studies report

421 unimpaired response inhibition in $\mathrm{ICD}^{27,28}$.

422 Given reward sensitivity increases in Parkinson's disease patients while medicated ${ }^{73,74}$, 423 our results support a bias towards enhanced incentive salience that puts constraints on the 424 controlling functions of the addicted brain. The incentive salience hypothesis ${ }^{75}$ suggests 425 combinations of previously acquired cue-reward associations may put significant 426 constraints over behaviour. In addition, the impaired response inhibition and salience 427 attribution model proposes both systems as responsible in guiding patients towards 428 addiction $^{76}$. Given emotional inputs deactivate essential cognitive control regions ${ }^{77}$, 429 presence of previously experienced sexual cues shall downgrade top-down control and 430 permit uncontrolled sexual behaviour to occur. Thus, prior reports showing intact 431 cognitive control abilities in $\mathrm{ICD}^{27,28}$ may be re-framed as a net effect on inhibition, as no 432 inputs from cue-reward associations were currently influencing patients' behaviour. Our 433 results go in line with both enhanced sensitivity to sexual cues together with reductions 434 in response inhibition ability, consistent with the inhibition and salience attribution $435 \operatorname{model}^{76}$.

\section{Dysfunctional circuitry in hypersexuality: functional and anatomical changes}

437 The circuitry mediating sexual events in healthy people activates limbic areas such as the 438 ventral striatum, amygdala, ACC, parietal and orbitofrontal cortex ${ }^{78-81}$. Controlling 439 sexual actions, in contrast, recruits specific regions of the inhibitory network including 
medRxiv preprint doi: https://doi.org/10.1101/2022.01.25.22269798; this version posted January 25, 2022. The copyright holder for this preprint (which was not certified by peer review) is the author/funder, who has granted medRxiv a license to display the preprint in It is made available under a CC-BY-NC.

Hypersexuality alters cognitive control

440 the pre-SMA, inferior-frontal gyrus, superior parietal cortex and $\mathrm{ACC}^{82-84}$. Here, we 441 found increased limbic (including ACC, VTA and caudate) and pre-SMA activity during 442 response inhibition under sexual influence in PD+HS patients (on vs. off medication) 443 compared to PD-HS patients (Figure 2C).

444 We interpret these findings as an abnormal mesocorticolimbic enhancement without 445 controlling functions leading to PD+HS. Upon a faulty mesocorticolimbic circuitry due 446 to dopamine agonists, including the VTA, ACC and ventral striatum ${ }^{85,86}$, enhanced 447 "wanting" may thus lead to "hard to resist" reward compulsive search ${ }^{38,87,88}$. Hence, the 448 combined "wanting" and "hard to resist" elements may integrate the neurobiological 449 foundations of hypersexual behaviour often found in Parkinson's disease patients. 450 PD+HS patients reported heightened sexual desire after task performance (Table 2), 451 which may require a larger cortical recruitment to generate some form of controlled 452 behaviour. Thus, a combination of dysfunctional dopaminergic bottom-up (limbic) and 453 top-down (executive) control under medication may boost uncontrolled desire in our 454 patients, explained by the combination of regions here reported. This view matches well according to the dual control model of sexual response ${ }^{89}$, where a shared duality between sexual excitatory and inhibitory mechanisms regulates sexual behaviour. Together with their model, plasticity alterations after persistent reward cue-exposure ${ }^{75,90}$ may predispose one of the two dual systems to set disproportional high sexual excitation or disproportional low sexual inhibition. Our results support the view that an enhanced sexual excitation system along the mesocorticolimbic system finds no or reduced opposition from prefrontal top-down control regions, leading to perturbed control of sexual behaviour.

463 Yet, it is difficult to understand how the causality and directionality of active task-based 464 fMRI regions are involved in PD+HS. As revealed by a winning functional connectivity 465 model (Figure 3B), the pre-SMA and its connectivity with the caudate put forward 2 466 pathophysiological assumptions in the hypersexual circuit: the pre-SMA showed a 467 reduced response to task-related signals and weakened its excitatory connection with the caudate (Figure 3C). Such top-down dysfunctional connection (based on dynamic causal modelling) was linked to an anatomical increase (based on fractional anisotropy tracts) in PD+HS (approaching significance values). Ultimately, opposite correlations between patients were seen between the pre-SMA-caudate tract and SSRT, which altogether suggests a dual neurobiological problem (local and descending pre-SMA connectivity) in 
medRxiv preprint doi: https://doi.org/10.1101/2022.01.25.22269798; this version posted January 25, 2022. The copyright holder for this preprint (which was not certified by peer review) is the author/funder, who has granted medRxiv a license to display the preprint in It is made available under a CC-BY-NC.

Hypersexuality alters cognitive control

473 the cognitive control network ${ }^{91,92}$. Thus, reductions in top-down control rely upon

474 paradoxical increases of white matter integrity, a possible neural compensatory response

475 previously reported in Parkinson's disease and $\mathrm{ICD}^{72,93,94}$.

476 The neurobiological changes in pre-SMA to caudate connectivity in our PD+HS sample

477 may be explained by repeated exposure to sexual cues and plasticity changes, boosted by

478 dopaminergic medication. Compulsive overuse of sexual acts may lead to frequent 479 engagement and overflow activity in pre-SMA-caudate connections, which could re480 organize the local activity and white matter pathways ${ }^{72}$. Possibly, aberrant plasticity along 481 this pathway may increase the vulnerability to develop PD+HS and other forms of 482 addictive behaviours as well. Together with notions that the mesocorticolimbic circuitry 483 is overstimulated in Parkinson's disease and $\mathrm{ICD}^{4}$, pre-SMA-caudate tract may be a 484 susceptible pathway to drug-induced dopaminergic overstimulation and hypersexuality 485 in Parkinson's disease. Hence, considering the well-known plasticity changes associated 486 to reward cue-exposure ${ }^{90}$, our results are interpreted by a remodeling framework of 487 inhibitory brain dynamics, possibly mediated by experience-dependent synaptic 488 plasticity. This view would explain why some Parkinson's disease patients develop a 489 particular form of ICD, coherent with founded notions of personality traits that influence 490 generation of ICD in Parkinson's disease ${ }^{5,95}$. Yet, further information is needed to 491 determine whether these neurobiological changes are causal or putative consequences of 492 dopaminergic medication in PD+HS.

\section{A route towards rehabilitation: neuromodulation to repair hypersexuality}

494 To date, hypersexuality counts with no direct validated treatment. With aim improving 495 this deficient clinical scenario, we compared excitatory rTMS stimulation over the pre496 SMA to a sham condition and found an acute benefit on response inhibition under sexual 497 influence in PD+HS patients (Figure 5B). We favored stimulation of the pre-SMA based 498 on 2 foundations: its dominant role in response inhibition ${ }^{20,23}$ and our fMRI group-based 499 findings showing pre-SMA causal downregulation in stop-related trials in PD+HS. Based 500 on previous rTMS beneficial effects over response inhibition ${ }^{96-98}$ and the excitability 501 properties of intermittent theta burst stimulation over the pre-SMA while performing 502 inhibitory tasks ${ }^{98}$, we assume our protocol enhanced pre-SMA inhibitory function. 503 Similarly, changes in the connectivity between pre-SMA and caudate may explain the 504 behavioural enhancement due to their direct functional connection in response inhibition 
medRxiv preprint doi: https://doi.org/10.1101/2022.01.25.22269798; this version posted January 25, 2022. The copyright holder for this preprint (which was not certified by peer review) is the author/funder, who has granted medRxiv a license to display the preprint in It is made available under a CC-BY-NC.

perpetuity. 4.0 International license.

Hypersexuality alters cognitive control

$505 \operatorname{tasks}^{91}$. Thus, intermittent theta burst stimulation may reset dysfunctional pre-SMA

506 downstream pathways and induce distant control over limbic networks in PD+HS

507 patients.

508 An alternative explanation of our neuromodulation findings is a possible variation on the

509 emotional regulation associated to sexual cues. Previously, a single-blind, randomized

510 crossover study investigated the impact of pre-SMA stimulation (online interference with

5115 pulses at $10 \mathrm{~Hz}$; sham-controlled) on a facial emotion recognition task ${ }^{99}$. After

512 stimulation periods, a specific downregulation in happiness recognition was disrupted

513 compared to sham ${ }^{99}$, suggestive of an influence on the rewarding system when

514 stimulating the pre-SMA. In line with such findings, our protocol could have produced

515 an impact on how sexual cues were identified in our patients and thus may have placed

516 less constraints over response inhibition.

517 Recent evidence suggests the efficacy of rTMS in improving response inhibition in

518 Parkinson's disease when applied over the dorsolateral prefrontal cortex ${ }^{100}$. Yet, to our

519 best knowledge, no studies have targeted the pre-SMA with aim modifying cognitive

520 control in Parkinson's disease with or without ICDs. Interestingly, however, pre-SMA

521 stimulation $(1 \mathrm{~Hz})$ improved Parkinson's disease-related dyskinesias ${ }^{101}$ - involuntary

522 movements induced by dopaminergic mediation - that might belong to a related

523 continuum of the motor circuits. Hence, their results may parallel our findings as their

524 stimulation protocol may have temporarily modified related pathophysiological

525 mechanisms $^{4}$ as those speculated here and possibly may offer a common target to lessen

526 dopaminergic side-effects.

\section{Strengths, limitations, and conclusions}

528 One strength of this study was using a highly selected clinical sample and ad-hoc stimuli

529 to provoke PD+HS measured with multi-level neuroimaging tools. We then used a

530 circuit-based approach to stimulate a putative brain target essential in PD+HS. Our

531 findings are based on a moderate sample size that should be expanded in larger cohorts.

532 Reasons for this sample size are directly related to the scientific question that requires to

533 limit recruitment to a precise clinical characteristic (with added recruitment efforts). Yet,

534 both studies follow adequate sample sizes based on previous neuroimaging ${ }^{10,38}$ and rTMS

535 studies on Parkinson's disease and ICD samples ${ }^{35}$. Moreover, our Bayesian sequential

536 analysis suggests the accumulation of evidence in favor of the alternative hypothesis 
medRxiv preprint doi: https://doi.org/10.1101/2022.01.25.22269798; this version posted January $25,2022$. The copyright holder for this preprint (which was not certified by peer review) is the author/funder, who has granted medRxiv a license to display the preprint in It is made available under a CC-BY

perpetuity. 4.0 International license.

Hypersexuality alters cognitive control

537 increases relatively steep as subjects are tested toward strong and moderate evidence in

538 study 1 and 2, respectively.

539 Stimulation of pre-SMA was conducted in PD+HS patients and not patients without the

540 behavioural problem. Thus, this design constraint renders our results not specific to

541 hypersexual issues. Yet, using sham-controlled stimulation (with ad-hoc sham rTMS

542 equipment) provides specificity of the neuromodulation target and protocol. Moreover,

543 given most Parkinson's disease patients without ICD have no associated non-motor

544 symptoms directly associated with pre-SMA functions (executive functions, response

545 inhibition, conflict resolution, etc.), ethical issues are applicable when testing stimulation

546 protocols in patients without a primary motive.

\section{Conclusion}

548 Evidence for an incentive sensitization framework is provided to explain the interplay

549 between desire enhancement and response inhibition in hypersexuality. We reveal a

550 circuit-based route that deciphers the cortico-striatal anatomical and functional

551 dysfunction and a candidate brain target for neuromodulation to change behavioural 552 expression in patients with PD+HS.

\section{Acknowledgements}

We are thankful for patients and their families for active engagement in the studies. We also are grateful to Federación de Parkinson for helping with advertising the study.

\section{Funding}

Funding included Fundación Jesús de Gangoiti Barrera (DMM), AES-ISCIII-Miguel Servet (CP18/00038) and AES-ISCIII (PI19/00298) (IO) for execution of the project. 
medRxiv preprint doi: https://doi.org/10.1101/2022.01.25.22269798; this version posted January 25, 2022. The copyright holder for this preprint (which was not certified by peer review) is the author/funder, who has granted medRxiv a license to display the preprint in It is made available under a CC-BY-NC. perpetuity.

Hypersexuality alters cognitive control

\section{Competing interests}

Dr. Raúl Martínez-Fernández reports honoraria for lecturing from Zambon, Boston Scientific and Abbvie. All other authors report no biomedical financial interests or potential competing interests.

\section{Supplementary material}

Supplementary material is available.

\section{References}

1. Molina JA, Sáinz-Artiga MJ, Fraile A, et al. Pathologic gambling in Parkinson's disease: a behavioral manifestation of pharmacologic treatment? Mov Disord. 2000;15(5):869-872. doi:10.1002/1531-8257(200009)15:5<869::aidmds1016>3.0.co;2-i

2. Weintraub D, Koester J, Potenza MN, et al. Impulse control disorders in Parkinson disease: A cross-sectional study of 3090 patients. Arch Neurol. 2010;67(5):589595. doi:10.1001/archneurol.2010.65

3. Voon V, Gao J, Brezing C, et al. Dopamine agonists and risk: Impulse control disorders in Parkinson's; Disease. Brain. Published online 2011. doi:10.1093/brain/awr080

4. Voon V, Napier TC, Frank MJ, et al. Impulse control disorders and levodopainduced dyskinesias in Parkinson's disease: an update. Lancet Neurol. 2017;16(3):238-250. doi:10.1016/S1474-4422(17)30004-2

5. Weintraub D, Claassen DO. Impulse Control and Related Disorders in Parkinson's Disease. In: International Review of Neurobiology. Vol 133. Academic Press Inc.; 2017:679-717. doi:10.1016/bs.irn.2017.04.006

6. Vriend C. The neurobiology of impulse control disorders in Parkinson's disease: from neurotransmitters to neural networks. Cell Tissue Res. 2018;373(1):327-336. doi:10.1007/s00441-017-2771-0

7. Goldstein RZ, Volkow ND. Dysfunction of the prefrontal cortex in addiction: neuroimaging findings and clinical implications. Nat Rev Neurosci. 2011;12(11):652-669. doi:10.1038/nrn3119

8. Napier TC, Corvol J-C, Grace AA, et al. Linking neuroscience with modern concepts of impulse control disorders in Parkinson's disease. Mov Disord. 2015;30(2):141-149. doi:10.1002/mds.26068

9. Djamshidian A, O'Sullivan SS, Wittmann BC, Lees AJ, Averbeck BB. Novelty seeking behaviour in Parkinson's disease. Neuropsychologia. Published online 2011. doi:10.1016/j.neuropsychologia.2011.04.026

10. Girard R, Obeso I, Thobois S, et al. Wait and you shall see: Sexual delay discounting in hypersexual Parkinson's disease. Brain. 2019;142(1):146-162. doi:10.1093/brain/awy298

11. Drew DS, Muhammed K, Baig F, et al. Dopamine and reward hypersensitivity in Parkinson's disease with impulse control disorder. Brain. 2020;143(8):2502-2518. 
medRxiv preprint doi: https://doi.org/10.1101/2022.01.25.22269798; this version posted January 25, 2022. The copyright holder for this preprint (which was not certified by peer review) is the author/funder, who has granted medRxiv a license to display the preprint in It is made available under a CC-BY

perpetuity.

Hypersexuality alters cognitive control

doi:10.1093/brain/awaa198

12. Biundo R, Formento-Dojot $\mathrm{P}$, Facchini $\mathrm{S}$, et al. Brain volume changes in Parkinson's disease and their relationship with cognitive and behavioural abnormalities. J Neurol Sci. 2011;310(1-2):64-69. doi:10.1016/j.jns.2011.08.001

13. Biundo R, Weis L, Facchini S, et al. Patterns of cortical thickness associated with impulse control disorders in Parkinson's disease. Mov Disord. 2015;30(5):688695. doi: $10.1002 / \mathrm{mds} .26154$

14. Tessitore A, Santangelo G, De Micco R, et al. Cortical thickness changes in patients with Parkinson's disease and impulse control disorders. Park Relat Disord. 2016;24:119-125. doi:10.1016/j.parkreldis.2015.10.013

15. Piray P, Zeighami Y, Bahrami F, Eissa AM, Hewedi DH, Moustafa AA. Behavioral/Cognitive Impulse Control Disorders in Parkinson's Disease Are Associated with Dysfunction in Stimulus Valuation But Not Action Valuation. $J$ Neurosci. 2014;34(23):7814-7824. doi:10.1523/JNEUROSCI.4063-13.2014

16. Leplow B, Sepke M, Schönfeld R, et al. Impaired learning of punishments in Parkinson's disease with and without impulse control disorder. J Neural Transm. 2017;124(2):217-225. doi:10.1007/s00702-016-1648-9

17. Martini A, Lago DD, Edelstyn NMJ, Grange JA, Tamburin S. Impulse control disorder in parkinson's disease: A meta-analysis of cognitive, affective, and motivational correlates. Front Neurol. 2018;9(AUG):654. doi:10.3389/fneur.2018.00654

18. Housden CR, O'Sullivan SS, Joyce EM, Lees AJ, Roiser JP. Intact reward learning but elevated delay discounting in Parkinson's disease patients with impulsivecompulsive spectrum behaviors. Neuropsychopharmacology. 2010;35(11):21552164. doi:10.1038/npp.2010.84

19. Voon V, Reynolds B, Brezing C, et al. Impulsive choice and response in dopamine agonist-related impulse control behaviors. Psychopharmacology (Berl). 2010;207(4):645-659. doi:10.1007/s00213-009-1697-y

20. Aron AR, Behrens TE, Smith S, Frank MJ, Poldrack RA. Triangulating a Cognitive Control Network Using Diffusion-Weighted Magnetic Resonance Imaging (MRI) and Functional MRI. J Neurosci. 2007;27(14):3743-3752. doi:10.1523/JNEUROSCI.0519-07.2007

21. Ray Li CS, Yan P, Sinha R, et al. Subcortical processes of motor response inhibition during a stop signal task. Neuroimage. 2008;41(4):1352-1363. doi:S1053-8119(08)00484-9 [pii] 10.1016/j.neuroimage.2008.04.023 [doi]

22. Rae CL, Hughes LE, Anderson MC, Rowe JB. The prefrontal cortex achieves inhibitory control by facilitating subcortical motor pathway connectivity. $J$ Neurosci. 2015;35(2):786-794. doi:10.1523/jneurosci.3093-13.2015

23. Zhang R, Geng X, Lee TMC. Large-scale functional neural network correlates of response inhibition: an fMRI meta-analysis. Brain Struct Funct. 2017;222(9):3973-3990. doi:10.1007/s00429-017-1443-X

24. Maizey L, Evans CJ, Muhlert N, Verbruggen F, Chambers CD, Allen CPG. Cortical and subcortical functional specificity associated with response inhibition. Neuroimage. 2020;220:117110. doi:10.1016/j.neuroimage.2020.117110

25. van Eimeren T, Pellecchia G, Cilia R, et al. Drug-induced deactivation of inhibitory networks predicts pathological gambling in PD. Neurology. 2010;75(19):1711-1716. doi:10.1212/WNL.0b013e3181fc27fa

26. Paz-Alonso PM, Navalpotro-Gomez I, Boddy P, et al. Functional inhibitory control dynamics in impulse control disorders in Parkinson's disease. Mov Disord. 2020;35(2):316-325. doi:10.1002/mds.27885 
medRxiv preprint doi: https://doi.org/10.1101/2022.01.25.22269798; this version posted January 25, 2022. The copyright holder for this preprint (which was not certified by peer review) is the author/funder, who has granted medRxiv a license to display the preprint in It is made available under a CC-BY perpetuity.

perpetuity.

Hypersexuality alters cognitive control

27. Leroi I, Barraclough M, McKie S, et al. Dopaminergic influences on executive function and impulsive behaviour in impulse control disorders in Parkinson's disease. J Neuropsychol. 2013;7(2):306-325. doi:10.1111/jnp.12026

28. Claassen DO, Van Den Wildenberg WPMM, Harrison MB, et al. Proficient motor impulse control in Parkinson disease patients with impulsive and compulsive behaviors. Pharmacol Biochem Behav. 2015;129:19-25. doi:10.1016/j.pbb.2014.11.017

29. Haagensen BN, Herz DM, Meder D, Madsen KH, Løkkegaard A, Siebner HR. Linking brain activity during sequential gambling to impulse control in Parkinson's disease. NeuroImage Clin. 2020;27(May):102330. doi:10.1016/j.nicl.2020.102330

30. Esteban-Peñalba T, Paz-Alonso PM, Navalpotro-Gómez I, Rodríguez-Oroz MC. Functional correlates of response inhibition in impulse control disorders in Parkinson's disease. NeuroImage Clin. 2021;32:102822. doi:10.1016/j.nicl.2021.102822

31. Menon V, Uddin LQ. Saliency, switching, attention and control: a network model of insula function. Brain Struct Funct. 2010;214(5-6):655-667. doi:10.1007/S00429-010-0262-0

32. Mata-Marín D, Pineda-Pardo JÁ, Molina JA, Alonso-Frech F, Vela L, Obeso I. Aberrant salient and corticolimbic connectivity in hypersexual Parkinson's disease. Brain Connect. Published online April 3, 2021. doi:10.1089/brain.2020.0868

33. Verbruggen F, De Houwer J. Do emotional stimuli interfere with response inhibition? Evidence from the stop signal paradigm. Cogn Emot. 2007;21(2):391403. doi:10.1080/02699930600625081

34. Pessoa L, Padmala S, Kenzer A, Bauer A. Interactions between cognition and emotion during response inhibition. Emotion. 2012;12(1):192-197. doi:10.1037/a0024109

35. Nardone R, De Blasi $\mathrm{P}$, Höller $\mathrm{Y}$, et al. Repetitive transcranial magnetic stimulation transiently reduces punding in Parkinson's disease: A preliminary study. J Neural Transm. Published online 2014. doi:10.1007/s00702-013-1100-3

36. Sverak T, Linhartova P, Fiala A, Kasparek T. Repetitive Transcranial Magnetic Stimulation Treating Impulsivity in Borderline Personality Disorder and Attention Deficit/Hyperactivity Disorder. In: Transcranial Magnetic Stimulation in Neuropsychiatry. InTech; 2018. doi:10.5772/intechopen.72787

37. Yang CC, Völlm B, Khalifa N. The Effects of rTMS on Impulsivity in Normal Adults: a Systematic Review and Meta-Analysis. Neuropsychol Rev. 2018;28(3):377-392. doi:10.1007/s11065-018-9376-6

38. Politis M, Loane $\mathrm{C}, \mathrm{Wu} \mathrm{K}$, et al. Neural response to visual sexual cues in dopamine treatment-linked hypersexuality in Parkinson's disease. Brain. 2013;136(2):400411. doi:10.1093/brain/aws326

39. Prévost C, Pessiglione M, Météreau E, et al. Separate valuation subsystems for delay and effort decision costs. J Neurosci. 2010;30(42):14080-14090. doi:10.1523/JNEUROSCI.2752-10.2010

40. Verbruggen F, Aron AR, Band GPH, et al. A consensus guide to capturing the ability to inhibit actions and impulsive behaviors in the stop-signal task. Elife. 2019;8. doi:10.7554/eLife.46323

41. Nasreddine ZS, Phillips NA, Bédirian V, et al. The Montreal Cognitive Assessment, MoCA: A brief screening tool for mild cognitive impairment. $J$ Am Geriatr Soc. Published online 2005. doi:10.1111/j.1532-5415.2005.53221.x 
medRxiv preprint doi: https://doi.org/10.1101/2022.01.25.22269798; this version posted January 25, 2022. The copyright holder for this preprint (which was not certified by peer review) is the author/funder, who has granted medRxiv a license to display the preprint in It is made available under a CC-BY-NC. perpetuity.

Hypersexuality alters cognitive control

42. Weschler D. Wechsler Adult Intelligence Scale - Fourth Edition. Stat Solut. Published online 2008. doi:10.1080/00268978500101581

43. Patton JH, Stanford MS, Barratt ES. Factor structure of the Barratt impulsiveness $\begin{array}{llll}\text { scale. } & J & \text { Clin } & \text { Psychol. }\end{array}$ http://www.ncbi.nlm.nih.gov/pubmed/8778124

44. Yesavage JA, Brink TL, Rose TL, et al. Development and validation of a geriatric depression screening scale: A preliminary report. J Psychiatr Res. 1982;17(1):3749. doi:10.1016/0022-3956(82)90033-4

45. Starkstein SE, Mayberg HS, Preziosi TJ, Andrezejewski P, Leiguarda R, Robinson RG. Reliability, validity, and clinical correlates of apathy in Parkinson's disease. J Neuropsychiatry Clin Neurosci. 1992;4(2):134-139. doi:10.1176/JNP.4.2.134

46. Beck AT, Epstein N, Brown G, Steer RA. An Inventory for Measuring Clinical Anxiety: Psychometric Properties. J Consult Clin Psychol. 1988;56(6):893-897. doi:10.1037/0022-006X.56.6.893

47. Mykletun A, Dahl AA, O’Leary MP, Fosså SD. Assessment of male sexual function by the Brief Sexual Function Inventory. BJU Int. 2006;97(2):316-323. doi:10.1111/j.1464-410X.2005.05904.X

48. Ashburner J, Friston KJ. Unified segmentation. Neuroimage. 2005;26(3):839-851. doi:10.1016/j.neuroimage.2005.02.018

49. Ashburner J. A fast diffeomorphic image registration algorithm. Neuroimage. Published online 2007. doi:10.1016/j.neuroimage.2007.07.007

50. Friston KJ, Harrison L, Penny W. Dynamic causal modelling. Hum Brain Funct Second Ed. 2003;19:1273-1302. doi:10.1016/B978-012264841-0/50054-8

51. Picard N, Strick PL. Motor areas of the medial wall: A review of their location and functional activation. Cereb Cortex. 1996;6(3):342-353. doi:10.1093/cercor/6.3.342

52. Inase M, Tokuno H, Nambu A, Akazawa T, Takada M. Corticostriatal and corticosubthalamic input zones from the presupplementary motor area in the macaque monkey: Comparison with the input zones from the supplementary motor area. Brain Res. 1999;833(2):191-201. doi:10.1016/S0006-8993(99)01531-0

53. Jahfari S, Waldorp L, van den Wildenberg WPM, Scholte HS, Ridderinkhof KR, Forstmann BU. Effective connectivity reveals important roles for both the hyperdirect (fronto-subthalamic) and the indirect (fronto-striatal-pallidal) frontobasal ganglia pathways during response inhibition. J Neurosci. 2011;31(18):68916899. doi:10.1523/JNEUROSCI.5253-10.2011

54. Robinson PA. Interrelating anatomical, effective, and functional brain connectivity using propagators and neural field theory. Phys Rev E - Stat Nonlinear, Soft Matter Phys. 2012;85(1):011912. doi:10.1103/PhysRevE.85.011912

55. Beier KT, Steinberg EE, Deloach KE, et al. Circuit Architecture of VTA Dopamine Neurons Revealed by Systematic Input-Output Mapping. Cell. 2015;162(3):622634. doi:10.1016/j.cell.2015.07.015

56. Macfarlane MD, Jakabek D, Walterfang M, et al. Striatal Atrophy in the Behavioural Variant of Frontotemporal Dementia: Correlation with Diagnosis, Negative Symptoms and Disease Severity. PLoS One. 2015;10(6). doi:10.1371/journal.pone.0129692

57. Neubert FX, Mars RB, Sallet J, Rushworth MFS. Connectivity reveals relationship of brain areas for reward-guided learning and decision making in human and monkey frontal cortex. Proc Natl Acad Sci U S A. 2015;112(20):E2695-E2704. doi:10.1073/pnas.1410767112

58. Elston TW, Bilkey DK. Anterior Cingulate Cortex Modulation of the Ventral 
medRxiv preprint doi: https://doi.org/10.1101/2022.01.25.22269798; this version posted January 25, 2022. The copyright holder for this preprint (which was not certified by peer review) is the author/funder, who has granted medRxiv a license to display the preprint in It is made available under a CC-BY perpetuity. perpetuity.

Hypersexuality alters cognitive control

Tegmental Area in an Effort Task. Cell Rep. 2017;19(11):2220-2230. doi:10.1016/j.celrep.2017.05.062

59. Stephan KE, Penny WD, Daunizeau J, Moran RJ, Friston KJ. Bayesian model selection for group studies. Neuroimage. 2009;46(4):1004-1017. doi:10.1016/j.neuroimage.2009.03.025

60. Gorgolewski K, Burns CD, Madison C, et al. Nipype: A Flexible, Lightweight and Extensible Neuroimaging Data Processing Framework in Python. Front Neuroinform. 2011;5:13. doi:10.3389/fninf.2011.00013

61. Esteban O, Ciric R, Finc K, et al. Analysis of task-based functional MRI data preprocessed with fMRIPrep. Nat Protoc. 2020;15(7):2186. doi:10.1038/S41596020-0327-3

62. Zhang H, Yushkevich PA, Alexander DC, Gee JC. Deformable registration of diffusion tensor MR images with explicit orientation optimization. Med Image Anal. 2006;10(5):764-785. doi:10.1016/j.media.2006.06.004

63. Wang R, Benner T, Sorensen AG, Wedeen VJ. Diffusion Toolkit: A Software Package for Diffusion Imaging Data Processing and Tractography. Proc Intl Soc Mag Reson Med. 2007;15:3720.

64. Yeatman JD, Dougherty RF, Myall NJ, Wandell BA, Feldman HM. Tract profiles of white matter properties: automating fiber-tract quantification. PLoS One. 2012;7(11). doi:10.1371/JOURNAL.PONE.0049790

65. PTSA. GitHub - pennmem/ptsa_new: PTSA - Python Time Series Analysis. Published online 2017.

66. Gramfort A. MEG and EEG data analysis with MNE-Python. Front Neurosci. 2013;7(7 DEC):267. doi:10.3389/fnins.2013.00267

67. Huang YZ, Edwards MJ, Rounis E, Bhatia KP, Rothwell JC. Theta burst stimulation of the human motor cortex. Neuron. 2005;45(2):201-206. doi:10.1016/j.neuron.2004.12.033

68. Stokes MG, Chambers CD, Gould IC, et al. Distance-adjusted motor threshold for transcranial magnetic stimulation. Clin Neurophysiol. 2007;118(7):1617-1625. doi:10.1016/j.clinph.2007.04.004

69. JASP Team. JASP (version 0.9.2)[Computer Software]. Published online 2021.

70. Bissett PG, Hagen MP, Jones HM, Poldrack RA. Design issues and solutions for stop-signal data from the adolescent brain cognitive development (Abcd) study. Elife. 2021;10. doi:10.7554/eLife.60185

71. Baudrexel S, Witte T, Seifried C, et al. Resting state fMRI reveals increased subthalamic nucleus-motor cortex connectivity in Parkinson's disease. Neuroimage. 2011;55(4):1728-1738. doi:10.1016/j.neuroimage.2011.01.017

72. Yoo H Bin, Lee JY, Lee JS, et al. Whole-brain diffusion-tensor changes in parkinsonian patients with impulse control disorders. J Clin Neurol. Published online 2015. doi:10.3988/jen.2015.11.1.42

73. Manohar SG, Husain M. Reduced pupillary reward sensitivity in Parkinson's disease. npj Park Dis. 2015;1(1):1-4. doi:10.1038/npjparkd.2015.26

74. Manohar SG, Chong TTJ, Apps MAJ, et al. Reward Pays the Cost of Noise Reduction in Motor and Cognitive Control. Curr Biol. 2015;25(13):1707-1716. doi:10.1016/j.cub.2015.05.038

75. Robinson TE, Berridge KC. Incentive-sensitization and addiction. Addiction. 2001;96(1):103-114. doi:10.1080/09652140020016996

76. Zilverstand A, Huang AS, Alia-Klein N, Goldstein RZ. Neuroimaging Impaired Response Inhibition and Salience Attribution in Human Drug Addiction: A Systematic Review. Neuron. 2018;98(5):886-903. 
medRxiv preprint doi: https://doi.org/10.1101/2022.01.25.22269798; this version posted January 25, 2022. The copyright holder for this preprint (which was not certified by peer review) is the author/funder, who has granted medRxiv a license to display the preprint in It is made available under a CC-BY perpetuity.

perpetuity.

Hypersexuality alters cognitive control

doi:10.1016/j.neuron.2018.03.048

77. Patterson TK, Lenartowicz A, Berkman ET, Ji D, Poldrack RA, Knowlton BJ. Putting the brakes on the brakes: negative emotion disrupts cognitive control network functioning and alters subsequent stopping ability. Exp Brain Res. 2016;234(11):3107-3118. doi:10.1007/s00221-016-4709-2

78. Arnow BA, Desmond JE, Banner LL, et al. Brain activation and sexual arousal in healthy, heterosexual males. Brain. 2002;125(5):1014-1023. doi:10.1093/brain/awf108

79. Hamann S, Herman RA, Nolan CL, Wallen K. Men and women differ in amygdala response to visual sexual stimuli. Nat Neurosci. 2004;7(4):411-416. doi:10.1038/nn1208

80. Walter M, Bermpohl F, Mouras H, et al. Distinguishing specific sexual and general emotional effects in fMRI-Subcortical and cortical arousal during erotic picture viewing. Published online 2008. doi:10.1016/j.neuroimage.2008.01.040

81. Cera N, Di Pierro ED, Sepede G, et al. The Role of Left Superior Parietal Lobe in Male Sexual Behavior: Dynamics of Distinct Components Revealed by fMRIj sm_2719 1602..1612. J Sex Med. 2012;9:1602-1612. doi:10.1111/j.17436109.2012.02719.x

82. Leon-Carrion J, Martín-Rodríguez JF, Damas-López J, et al. Does dorsolateral prefrontal cortex (DLPFC) activation return to baseline when sexual stimuli cease? The role of DLPFC in visual sexual stimulation. Neurosci Lett. 2007;416(1):5560. doi:10.1016/j.neulet.2007.01.058

83. Rodriguez-Nieto G, Sack AT, Dewitte M, Emmerling F, Schuhmann T. Putting out the blaze: The neural mechanisms underlying sexual inhibition. PLoS One. 2019;14(1):1-21. doi:10.1371/journal.pone.0208809

84. Seok J-W, Sohn J-H. Response inhibition during processing of sexual stimuli in males with problematic hypersexual behavior. J Behav Addict. 2020;9(1). doi:10.1556/2006.2020.00003

85. Reuter J, Raedler T, Rose M, Hand I, Gläscher J, Büchel C. Pathological gambling is linked to reduced activation of the mesolimbic reward system. Nat Neurosci. 2005;8(2):147-148. doi:10.1038/nn1378

86. Yau YHC, Leeman RF, Potenza MN. Biological Underpinning of Behavioural Addictions and Management Implications. In: Textbook of Addiction Treatment: International Perspectives. Springer Milan; 2015:1411-1442. doi:10.1007/978-88470-5322-9_71

87. Berridge KC, Robinson TE. Parsing reward. Trends Neurosci. 2003;26(9):507513. doi:10.1016/S0166-2236(03)00233-9

88. Georgiadis JR, Kringelbach ML. The human sexual response cycle: Brain imaging evidence linking sex to other pleasures. Prog Neurobiol. 2012;98(1):49-81. doi:10.1016/j.pneurobio.2012.05.004

89. Bancroft J, Janssen E. The dual control model of male sexual response: A theoretical approach to centrally mediated erectile dysfunction. Neurosci Biobehav Rev. 2000;24(5):571-579. doi:10.1016/S0149-7634(00)00024-5

90. Ostroumov A, Dani JA. Inhibitory Plasticity of Mesocorticolimbic Circuits in Addiction and Mental Illness. Trends Neurosci. 2018;41(12):898-910. doi:10.1016/j.tins.2018.07.014

91. Duann J-RR, Ide JS, Luo X, Li CSR. Functional connectivity delineates distinct roles of the inferior frontal cortex and presupplementary motor area in stop signal inhibition. $J \quad$ Neurosci. 2009;29(32):10171-10179. doi:29/32/10171 [pii]10.1523/JNEUROSCI.1300-09.2009 [doi] 
medRxiv preprint doi: https://doi.org/10.1101/2022.01.25.22269798; this version posted January 25, 2022. The copyright holder for this preprint (which was not certified by peer review) is the author/funder, who has granted medRxiv a license to display the preprint in It is made available under a CC-BY perpetuity.

Hypersexuality alters cognitive control

92. Schmidt CC, Timpert DC, Arend I, et al. Control of response interference: caudate nucleus contributes to selective inhibition. Sci Rep. 2020;10(1):1-15. doi:10.1038/s41598-020-77744-1

93. Chen N-K, Chou Y-H, Sundman M, et al. Alteration of Diffusion-Tensor Magnetic Resonance Imaging Measures in Brain Regions Involved in Early Stages of Parkinson's Disease. Brain Connect. 2018;8(6):343-349. doi:10.1089/brain.2017.0558

94. Sparks H, Riskin-Jones H, Price C, et al. Impulsivity Relates to Relative Preservation of Mesolimbic Connectivity in Patients with Parkinson Disease. NeuroImage Clin. 2020;27:102259. doi:10.1016/j.nicl.2020.102259

95. McDonald KR, Chilman E, Barraclough M, Elliott R, Leroi I. Personality Style in Behavioural Disturbances in Parkinson?s Disease. J Neurol Neurophysiol. 2014;05(06). doi:10.4172/2155-9562.1000251

96. Obeso I, Cho SS, Antonelli F, et al. Stimulation of the pre-SMA influences cerebral blood flow in frontal areas involved with inhibitory control of action. Brain Stimul. Published online 2013. doi:10.1016/j.brs.2013.02.002

97. Zandbelt BB, Bloemendaal M, Hoogendam JM, Kahn RS, Vink M. Transcranial Magnetic Stimulation and Functional MRI Reveal Cortical and Subcortical Interactions during Stop-signal Response Inhibition. $J$ Cogn Neurosci. 2013;25(2):157-174. doi:10.1162/jocn_a_00309

98. Watanabe T, Hanajima R, Shirota Y, et al. Effects of rTMS of pre-supplementary motor area on fronto basal ganglia network activity during stop-signal task. $J$ Neurosci. 2015;35(12):4813-4823. doi:10.1523/JNEUROSCI.3761-14.2015

99. Rochas V, Gelmini L, Krolak-Salmon P, et al. Disrupting pre-SMA activity impairs facial happiness recognition: An event-related TMS study. Cereb Cortex. 2013;23(7):1517-1525. doi:10.1093/cercor/bhs133

100. Jiang Y, Guo Z, McClure MA, He L, Mu Q. Effect of rTMS on Parkinson's cognitive function: a systematic review and meta-analysis. BMC Neurol. 2020;20(1):1-14. doi:10.1186/s12883-020-01953-4

101. Lohse A, Meder D, Nielsen S, et al. Low-frequency transcranial stimulation of presupplementary motor area alleviates levodopa-induced dyskinesia in Parkinson's disease: a randomized cross-over trial. Brain Commun. 2020;2(2). doi:10.1093/BRAINCOMMS/FCAA147 
medRxiv preprint doi: https://doi.org/10.1101/2022.01.25.22269798; this version posted January 25,2022 . The copyright holder for this preprint (which was not certified by peer review) is the author/funder, who has granted medRxiv a license to display the preprint in It is made available under a

perpetuity.

Hypersexuality alters cognitive control

\section{Supplementary Material}

\section{A circuit-based approach to repair hypersexuality in Parkinson's disease}

David Mata-Marín ${ }^{1,2,6 *}$, José A. Pineda-Pardo ${ }^{1,2 *}$, Mario Michiels ${ }^{1,2,6}$, Cristina Pagge $^{1,2,6}$, Claudia Ammann ${ }^{1,2}$, Raúl Martínez-Fernández ${ }^{1,2}$, José Antonio Molina ${ }^{3}$, Lydia Vela ${ }^{4}$, Fernando Alonso-Frech ${ }^{5}$, Ignacio Obeso ${ }^{1,2}$

*Co-first authors

\section{Author affiliations:}

1 HM CINAC. Centro Integral de Neurociencias AC. HM Puerta del Sur. HM Hospitales. Móstoles, Madrid, Spain.

2 Network Center for Biomedical Research on Neurodegenerative Diseases (CIBERNED), Instituto Carlos III, Madrid, Spain.

3 Hospital 12 de Octubre, Madrid, Spain.

4 Hospital Fundación Alcorcón, Madrid, Spain.

5 Hospital Clínico San Carlos, Madrid, Spain.

$6 \mathrm{PhD}$ program in Neuroscience, Autonoma de Madrid University, 28029 Madrid, Spain.

Correspondence to: Dr. Ignacio Obeso.

Avda. Carlos V, 70 Móstoles, 28938, Madrid, Spain.

iobeso.hmcinac@hmhospitales.com

www.controlandhabit.com

Running title: Hypersexuality alters cognitive control. 
medRxiv preprint doi: https://doi.org/10.1101/2022.01.25.22269798; this version posted January 25, 2022. The copyright holder for this preprint (which was not certified by peer review) is the author/funder, who has granted medRxiv a license to display the preprint in It is made available under a CC-BY

perpetuity. 4.0 International license .

Hypersexuality alters cognitive control

553 Methods

554 The erotic stop-signal task

555 Following the recommendations for using the stop signal paradigm ${ }^{1}$, we first evaluated

556 the independence of the go and stop processes by: a) correlations between StopRespond

557 reaction times (RTs) and correct go trials of each stimuli condition (erotic and non-erotic)

558 per participant; b) correlations between the go trials and stop signal reaction time (SSRT);

559 and c) plotting cumulative distributions of Go and StopRespond RTs (Figure 1C, 5A).

560 Bonferroni correction for multiple comparisons were used in post-hoc tests and specified

561 when tests did not survive corrections.

562 Dynamic causal modelling (DCM)

563 DCM estimates the effective connectivity between brain regions according to (i) average

564 connections between regions (DCM.A), (ii) modulatory task influence on connections

565 (erotic images and Stop-Inhibit in erotic trials, see Figure 3A; DCM.B) and (iii)

566 condition-specific inputs that drive network activity (namely regional engagement in a

567 Stop-Inhibit task; DCM.C). Across all 13 models, driving inputs (DCM.C) represented 2

568 key elements of the task: erotic images and Stop-Inhibit tasks. This was set to both ACC

569 and pre-SMA areas (Figure S1). Bayesian parameter averaging and was used to estimate

570 the connectivity values of the most likely model at the group level ${ }^{2}$.

571 DWI acquisition and preprocessing steps

572 Marchenko-Pastur distribution principal component analysis (MP-PCA) denoising

573 following MRtrix3's dwidenoise ${ }^{3}$ was applied with a 5-voxel window. After MP-PCA,

574 B1 field inhomogeneity was corrected using dwibiascorrect from MRtrix3 with the N4

575 algorithm ${ }^{4}$. After B1 bias correction, the mean intensity of the DWI series was adjusted 
medRxiv preprint doi: https://doi.org/10.1101/2022.01.25.22269798; this version posted January 25, 2022. The copyright holder for this preprint (which was not certified by peer review) is the author/funder, who has granted medRxiv a license to display the preprint in It is made available under a CC-BY-NC-ND 4.0 International license .

Hypersexuality alters cognitive control

576 so all the mean intensity of the $b=0$ images matched across each separate DWI scanning

577 sequence. FSL (version 6.0.3:b862cdd5) eddy was used for head motion correction and

578 Eddy current correction ${ }^{5}$. Eddy was configured with a $q$-space smoothing factor of 10 , a

579 total of 5 iterations, and 1000 voxels used to estimate hyperparameters. A linear first level

580 model and a linear second level model were used to characterize Eddy current-related

581 spatial distortion. $q$-space coordinates were forcefully assigned to shells. Field offset was

582 attempted to be separated from subject movement. Shells were aligned post-eddy. Eddy's

583 outlier replacement was run $^{6}$. Data were grouped by slice, only including values from

584 slices determined to contain at least 250 intracerebral voxels. Groups deviating by more

585 than 4 standard deviations from the prediction had their data replaced with imputed

586 values. $b=0$ reference image was collected with reversed phase-encode blips, resulting in

587 a pair of images with distortions going in opposite directions. Here, $b=0$ images with

588 reversed phase encoding directions were used along with an equal number of $b=0$ images

589 extracted from the DWI scans. From these pairs the susceptibility-induced off-resonance

590 field was estimated ${ }^{7}$. The fieldmaps were ultimately incorporated into the Eddy current

591 and head motion correction interpolation. Final interpolation was performed using the jac

592 method.

593 Several confounding time-series were calculated based on the preprocessed DWI:

594 framewise displacement (FD) using the implementation in Nipype (following the

595 definitions by Power et al. ${ }^{8}$ ) The head-motion estimates calculated in the correction step

596 were also placed within the corresponding confounds file. Slice-wise cross correlation

597 was also calculated. The DWI time-series were resampled to ACPC, generating a

598 preprocessed DWI run in ACPC space with $1.2 \mathrm{~mm}$ isotropic voxels. Several internal

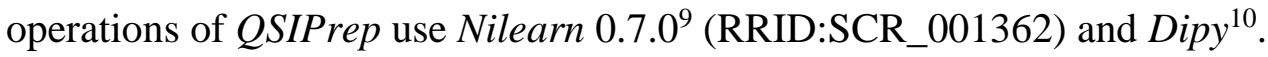


medRxiv preprint doi: https://doi.org/10.1101/2022.01.25.22269798; this version posted January $25,2022$. The copyright holder for this preprint (which was not certified by peer review) is the author/funder, who has granted medRxiv a license to display the preprint in It is made available under a perpetuity

perpetuity.

Hypersexuality alters cognitive control

600

\section{Tract selection}

601 We ran the default fiber tracking algorithm using DsiStudio ${ }^{11}$ with 1000000 seeds to 602 select the tracts of interest (HCP1065 atlas). Based on the DCM results, we selected ROIs

603 extracted from the AAL_2mm atlas (except for VTA: AAL_1mm) and the pre-SMA

604 (HMAT 2mm atlas) ${ }^{12}$. Tracts were obtained by setting the first region as seed (e.g., 605 caudate) and the end region as end (e.g., pre-SMA). However, the right caudate to ACC 606 tract were both set as ROI to obtain a higher number of streamlines.

607 Then, streamlines were cut to avoid limiting access into the seed region. Finally, we 608 deleted residual short tracts produced by cutting the tracts outside the seed region by 609 setting the threshold to $10 \mathrm{~mm}$. For left caudate-ACC, we additionally deleted repeated 610 tracts using the corresponding DsiStudio function (voxel threshold $=1$ ). For right VTA611 caudate, the straight streamline was removed since the tracking algorithm was not able to 612 recognize the tracts streamlines from one of the hemispheres.

613 These bundles were used as a reference to extract the corresponding bundles from each 614 subject. For this, we set to 20 the number of points to define each streamline and then we 615 ran the recoBundles method implemented by Dipy with the default options.

616 Results

\section{Behavioural results}

618 While $p$ (inhib) did not significantly differ between groups $\left[F^{\prime} \mathrm{s}>1\right]$, it varied from $50 \%$

619 (Table S1) thus using the integration SSRT method is recommended ${ }^{1}$. Moreover, 620 probability distributions were faster for StopRespond RT compared to go trials in every 621 group [Kolmogorov-Smirnov: $p$ 's $>.05$; except for PD-HS off medication $p=.06$; Figure 
medRxiv preprint doi: https://doi.org/10.1101/2022.01.25.22269798; this version posted January 25, 2022. The copyright holder for this preprint (which was not certified by peer review) is the author/funder, who has granted medRxiv a license to display the preprint in It is made available under a perpetuity. perpetuity.

Hypersexuality alters cognitive control

622 1C]. Last, independence between going and stopping on erotic trials was confirmed with

623 non-significant correlations between both measures (go and SSRT) across groups

$624[p$ 's $>.05, r$ 's $>$.4]. The faster StopRespond RT compared to Go RT independence between

625 go and stop are all in line with a race model of action cancellation. Mean stop signal delay

626 (SSD) across groups did not vary significantly between groups nor between conditions

627 (Table S1).

628 Response initiation assessed by Go trials revealed an effect of condition $\left[F_{(2,44)}=7.59\right.$,

$629 p=.009]$ and condition $\mathrm{x}$ group interaction $\left[F_{(2,44)}=4.45, p=.017\right]$ were found. Post-hoc

630 comparisons on Go RTs did not survive Bonferroni corrections. The length of SSD was

631 not different across groups, nor it revealed significant interactions [ $\left.F^{\prime} \mathrm{s}>1\right]$.

632 Sexual influence over response inhibition (SSRT) was highly dependent on medication,

633 group and condition (group $\left[F_{(2,44)}=7.07, p=.002\right]$; medication $\mathrm{x}$ group $\left[F_{(2,44)}=5.92, p\right.$

$634=.006]$; medication $\mathrm{x}$ condition $\left[F_{(2,40)}=8.25, p=.006\right]$; medication $\mathrm{x}$ group $\mathrm{x}$ condition

$\left.635\left[F_{(2,40)}=5.96, p=.005\right]\right)$. Specifically, faster SSRT in erotic trials were seen in PD+HS

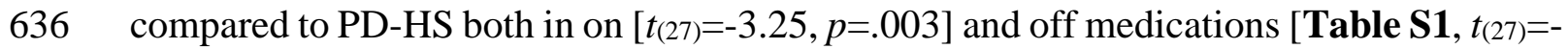

$6378.72, p<.001]$. Similar differences were present between patients groups in non-erotic

638 conditions while on $\left[t_{(27)}=-3.72, p=.001\right]$ and off medications [Table S1, $t_{(27)}=-6.57$,

$639 p<.001]$. The group effects were marked by faster SSRT (erotic condition) in PD+HS (off

640 medicated) compared to PD-HS [on: $t_{(27)}=-3.25, p=.003 ;$ off: $\left.t_{(27)}=-8.72, p<.001\right]$ and

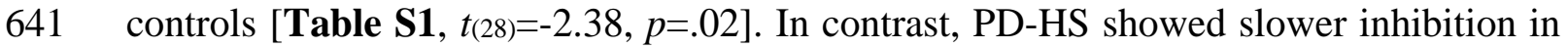

642 both erotic and non-erotic conditions compared to controls [Table S1, $t$ 's $s$ 2.1; $p$ 's<.3].

643 Medication effects across conditions revealed an specific worsening of inhibition in

644 PD+HS patients while on compared to off medication [Table S1, $t_{(12)}=-3.06, p=.01$ ], an

645 effect not seen in the non-erotic condition [Table S1, $t^{\prime} s<.1 ; p<.8$ ]. Error rates were not

646 significantly different across groups, medication, or condition [z's<1]. Significant 
medRxiv preprint doi: https://doi.org/10.1101/2022.01.25.22269798; this version posted January $25,2022$. The copyright holder for this preprint (which was not certified by peer review) is the author/funder, who has granted medRxiv a license to display the preprint in It is made available under a CC-rpetuity.

perpetuity.

Hypersexuality alters cognitive control

647 difference in response adaptation on the response delay effect (RDE) was seen (Go erotic

648 minus Go non-erotic RTs) in the PD+HS group between medication states [on: -.22 \pm 11.9 ;

649 off: $13.87 \pm 17.48 ; p<.03$ ], while non-significant in the PD-HS group [on: $-5.40 \pm 2.3$; off:

$650 \quad 0.84 \pm 14.44 ; p<.35]$.

\section{Classic stop signal task}

652 To determine whether impulsive actions were associated only to presence of erotic

653 stimuli, we assessed performance on a classic stop signal task (without presence of erotic

654 images). Patients and controls probabilities of inhibition were not close to $50 \%$ although

655 no significant differences were found between groups $\left[F_{(2,44)}=.31, p=.73\right]$. The SSRT

656 showed significant differences between groups $\left[F_{(2,44)}=7.13, p=.002\right]$, whereby post-hoc

657 tests result in prolonged SSRT in the PD-HS group compared to PD+HS patients $\left[t_{(28)}=-\right.$

$6583.07, p=.005]$ and controls $\left[t_{(28)}=3.07, p=.001\right]$. The remaining variables on the classic

659 stop signal task showed non-significant differences between the groups.

\section{0 fMRI results}

\section{Neural Network for successful inhibition under erotic influence}

662 To eliminate confounding factors of the motor response embedded within inhibition of

663 ongoing actions, Stop-Inhibit vs. Go trials were compared showing a main Group effect,

664 with significant clusters over the motor cortex and cerebellum (Table S2). Such effect

665 was driven by the PD-HS group showing greater ACC activity than PD+HS hypersexual

666 patients (off medication; Table S2). 
medRxiv preprint doi: https://doi.org/10.1101/2022.01.25.22269798; this version posted January 25, 2022. The copyright holder for this preprint (which was not certified by peer review) is the author/funder, who has granted medRxiv a license to display the preprint in It is made available under a CC-BY-NC

perpetuity. 4.0 International license.

Hypersexuality alters cognitive control

\section{Non-invasive brain stimulation: aiming to restore hypersexual}

\section{8 behaviour}

669 Probability of inhibition substantially deviated from 50\% in both real and sham ( 70\%;

670 Table S5), thus we used the integrative approach to estimate SSRT values No significant

671 differences in SSD were observed in any type of stimuli after either condition (Table S5).

672 Although not statistically significant, after real intermittent theta burst stimulation

673 (compared to sham) patients produced less premature errors - anticipations during the

674 sexual cue- in both erotic and non-erotic stimuli and tended to produce faster RTs in go

675 trials (Table S5). Analyses were repeated comparing first vs. second sessions

676 (independently of stimulation condition) to control for potential undesired order effects.

677 No significant order effect was observed for any of the task variables including SSRT

$678\left[F^{\prime} s>1\right]$. No significant difference in response adaptation on the response delay effect

679 (RDE: Go erotic minus Go non-erotic RTs) was seen in any condition [real: 12.01 \pm 21.08 ;

680 sham: $9.42 \pm 17.48 ; p=.90]$.

\section{Supplementary references}

1. Verbruggen F, Aron AR, Band GPH, et al. A consensus guide to capturing the ability to inhibit actions and impulsive behaviors in the stop-signal task. Elife. 2019;8. doi:10.7554/eLife.46323

2. Stephan KE, Penny WD, Daunizeau J, Moran RJ, Friston KJ. Bayesian model selection for group studies. Neuroimage. 2009;46(4):1004-1017. doi:10.1016/j.neuroimage.2009.03.025

3. Veraart J, Novikov DS, Christiaens D, Ades-aron B, Sijbers J, Fieremans E. Denoising of diffusion MRI using random matrix theory. Neuroimage. 2016;142:394-406. doi:10.1016/j.neuroimage.2016.08.016

4. Tustison NJ, Avants BB, Cook PA, et al. N4ITK: Improved N3 bias correction. IEEE Trans Med Imaging. 2010;29(6):1310-1320. doi:10.1109/TMI.2010.2046908

5. Andersson JLR, Sotiropoulos SN. An integrated approach to correction for offresonance effects and subject movement in diffusion MR imaging. Neuroimage. 2016;125:1063-1078. doi:10.1016/j.neuroimage.2015.10.019 
medRxiv preprint doi: https://doi.org/10.1101/2022.01.25.22269798; this version posted January 25 , 2022. The copyright holder for this preprint (which was not certified by peer review) is the author/funder, who has granted medRxiv a license to display the preprint in It is made available under a CC-BY-NC-N

perpetuity. 4.0 International license.

Hypersexuality alters cognitive control

6. Andersson JLR, Graham MS, Zsoldos E, Sotiropoulos SN. Incorporating outlier detection and replacement into a non-parametric framework for movement and distortion correction of diffusion MR images. Neuroimage. 2016;141:556-572. doi:10.1016/j.neuroimage.2016.06.058

7. Andersson JLR, Skare S, Ashburner J. How to correct susceptibility distortions in spin-echo echo-planar images: Application to diffusion tensor imaging. Neuroimage. 2003;20(2):870-888. doi:10.1016/S1053-8119(03)00336-7

8. Power JD, Mitra A, Laumann TO, Snyder AZ, Schlaggar BL, Petersen SE. Methods to detect, characterize, and remove motion artifact in resting state fMRI. Neuroimage. 2014;84:320-341. doi:10.1016/j.neuroimage.2013.08.048

9. Abraham A, Pedregosa F, Eickenberg M, et al. Machine learning for neuroimaging with scikit-learn. Front Neuroinform. 2014;8(FEB):1-10. doi:10.3389/fninf.2014.00014

10. Garyfallidis E, Brett M, Amirbekian B, et al. Dipy, a library for the analysis of diffusion MRI data. Front Neuroinform. 2014;8:8.

11. Yeh F. DSI Studio. Published online June 2021. doi:10.5281/ZENODO.4978980

12. Mayka MA, Corcos DM, Leurgans SE, Vaillancourt DE. Three-dimensional locations and boundaries of motor and premotor cortices as defined by functional brain imaging: A meta-analysis. Neuroimage. 2006;31(4):1453-1474. doi:10.1016/j.neuroimage.2006.02.004 
medRxiv preprint doi: https://doi.org/10.1101/2022.01.25.22269798; this version posted January $25,2022$. The copyright holder for this preprint (which was not certified by peer review) is the author/funder, who has granted medRxiv a license to display the preprint in It is made available under a $\mathrm{C}$ erpetuity.

perpetuity.

Hypersexuality alters cognitive control

\section{Supplementary Tables}

Table S1 Erotic stop signal reaction time results per Medication and Group conditions.

\begin{tabular}{|c|c|c|c|c|c|}
\hline & $\begin{array}{c}\text { PD+HS } \\
\text { ON }\end{array}$ & $\begin{array}{c}\text { PD+HS } \\
\text { OFF }\end{array}$ & $\begin{array}{c}\text { PD-HS } \\
\text { ON }\end{array}$ & $\begin{array}{c}\text { PD-HS } \\
\text { OFF }\end{array}$ & Controls \\
\hline \multicolumn{6}{|l|}{ Erotic } \\
\hline $\mathrm{Go} \mathrm{RT}^{\mathrm{a}}(\mathrm{ms})$ & $643.11 \pm 191.5$ & $627.10 \pm 131.9$ & $628.31 \pm 108.0$ & $619.38 \pm 151.0$ & $525.29 \pm 79.6$ \\
\hline StopRespond RT (ms) & $327.35 \pm 154.3$ & $288.96 \pm 144.1$ & $285.42 \pm 169.9$ & $27.63 \pm 131.1$ & $176.84 \pm 39.8$ \\
\hline $\mathrm{p}(\mathrm{stop}) \%^{\mathrm{b}}$ & $64.03 \pm 17.4$ & $66.11 \pm 9.2$ & $66.72 \pm 16.6$ & $69.30 \pm 17.0$ & $69.54 \pm 13.8$ \\
\hline $\mathrm{SSD}^{\mathrm{c}}(\mathrm{ms})$ & $232.92 \pm 108.6$ & $277.65 \pm 117.2$ & $251.93 \pm 121.2$ & $243.59 \pm 133.7$ & $251.57 \pm 97.1$ \\
\hline $\operatorname{SSRT}^{\mathrm{d}}(\mathrm{ms})$ & $385.78 \pm 101.4$ & $29.98 \pm 92.9$ & $557.40 \pm 171.4$ & $667.55 \pm 132.1$ & $418.48 \pm 179.9$ \\
\hline $\mathrm{ZRFT}^{\mathrm{e}}(\mathrm{ms})$ & $0.06 \pm 0.4$ & $0.22 \pm 0.4$ & $-0.60 \pm 0.6$ & $-1.20 \pm 0.4$ & $-0.87 \pm 0.6$ \\
\hline $\begin{array}{l}\text { Discrimination } \\
\text { (total) }\end{array}$ & $2.07 \pm 1.2$ & $2.86 \pm 3.3$ & $2.73 \pm 4.1$ & $2.93 \pm 3.6$ & $2.44 \pm 5.8$ \\
\hline Premature errors & $0.64 \pm 1.6$ & $0.43 \pm 0.9$ & $0.20 \pm 0.5$ & $0.0 \pm 0.0$ & $0.13 \pm 0.3$ \\
\hline \multicolumn{6}{|l|}{ Non-Erotic } \\
\hline $\mathrm{Go} \mathrm{RT}^{\mathrm{a}}(\mathrm{ms})$ & $642.89 \pm 187.3$ & $64.98 \pm 125.2$ & $622.90 \pm 101.5$ & $62.23 \pm 152.1$ & $538.42 \pm 8.4$ \\
\hline StopRespond RT (ms) & $329.78 \pm 154.0$ & $282.08 \pm 152.9$ & $271.13 \pm 171.1$ & $265.37 \pm 135.1$ & $18.30 \pm 49.4$ \\
\hline $\mathrm{p}($ stop $) \%^{\mathrm{b}}$ & $65.21 \pm 15.1$ & $67.85 \pm 14.0$ & $69.36 \pm 17.9$ & $69.86 \pm 17.4$ & $69.05 \pm 15.7$ \\
\hline $\mathrm{SSD}^{\mathrm{c}}(\mathrm{ms})$ & $231.49 \pm 112.6$ & $279.49 \pm 116.4$ & $251.95 \pm 12.9$ & $246.93 \pm 132.0$ & $251.63 \pm 96.3$ \\
\hline $\operatorname{SSRT}^{\mathrm{d}}(\mathrm{ms})$ & $381.78 \pm 122.0$ & $38.79 \pm 72.6$ & $559.37 \pm 134.1$ & $677.71 \pm 152.6$ & $445.42 \pm 159.9$ \\
\hline $\mathrm{ZRFT}^{\mathrm{e}}(\mathrm{ms})$ & $0.08 \pm 0.5$ & $-0.08 \pm 0.3$ & $-0.70 \pm 0.6$ & $-1.12 \pm 0.4$ & $-0.94 \pm 1.7$ \\
\hline $\begin{array}{l}\text { Discrimination } \\
\text { (total) }\end{array}$ & $2.50 \pm 1.99$ & $2.36 \pm 3.2$ & $1.93 \pm 2.2$ & $2.71 \pm 4.5$ & $2.19 \pm 7.6$ \\
\hline Premature errors & $0.29 \pm 0.8$ & $0.14 \pm 0.3$ & $0.0 \pm 0.0$ & $0.0 \pm 0.0$ & $0.13 \pm 0.3$ \\
\hline
\end{tabular}

${ }^{\mathrm{a}} \mathrm{RT}=$ reaction time $;{ }^{b} p($ stop $) \%=\%$ probability of stopping; ${ }^{c} S S D=$ Stop Signal Delay; ${ }^{d}$ SSRT: Stop Signal Reaction Time; ${ }^{e}$ ZRFT: Zscore Relative Finish Time. 
medRxiv preprint doi: https://doi.org/10.1101/2022.01.25.22269798; this version posted January $25,2022$. The copyright holder for this preprint (which was not certified by peer review) is the author/funder, who has granted medRxiv a license to display the preprint in is made available under a perpetuity.

perpetuity.

Hypersexuality alters cognitive control

Table S2. Stop-Inhibit vs. Go trials in the erotic condition.

\begin{tabular}{lcccc} 
Tests and anatomical structures & $\mathbf{X}$ & $\mathbf{Y}$ & $\mathbf{Z}$ & T-value \\
\hline Group & & & & \\
Motor cortex & 20 & -36 & 60 & $5.71^{* *}$ \\
Cerebellum & 24 & -16 & 52 & $5.18^{* *}$ \\
& 20 & -44 & -28 & $4.52^{* *}$ \\
& 16 & -34 & -32 & $3.66^{* *}$
\end{tabular}

\section{PD-HS > PD+HS off}

Cingulate

Superior parietal lobe

Motor cortex
18

$26-24$

$20 \quad-36$

4.91

4.5

Tests and anatomical structures for the successful (stop-inhibit) vs go trials contrast in the erotic condition. $p<0.05$ FWE cluster-wise corrected; * $p<.005 ; * * p<.001$. 
medRxiv preprint doi: https://doi.org/10.1101/2022.01.25.22269798; this version posted January $25,2022$. The copyright holder for this preprint (which was not certified by peer review) is the author/funder, who has granted medRxiv a license to display the preprint in It is made available under a

perpetuity. 4.0 International license.

Hypersexuality alters cognitive control

Table S3. Stop Success vs Stop Fail under erotic condition.

\begin{tabular}{|c|c|c|c|c|}
\hline Tests and anatomical structures & $\mathbf{X}$ & $\mathbf{Y}$ & $\mathbf{Z}$ & T-value \\
\hline \multicolumn{5}{|l|}{ Medication } \\
\hline \multirow[t]{3}{*}{ Superior parietal lobe } & -44 & -24 & 46 & $4.18 * *$ \\
\hline & -50 & -30 & 50 & $3.86^{* *}$ \\
\hline & -46 & -38 & 52 & $3.41 * *$ \\
\hline Anterior cingulate cortex (ACC) & -12 & 10 & 40 & $3.75^{*}$ \\
\hline Pre-supplementary motor area (pre-SMA) & 6 & 20 & 56 & $3.41 *$ \\
\hline Supplementary motor area & 0 & -8 & 70 & $3.20 *$ \\
\hline \multicolumn{5}{|l|}{ PD+HS on $>$ off } \\
\hline Frontal pole & 16 & 62 & 18 & $4.44 * *$ \\
\hline Anterior cingulate cortex (ACC) & 0 & 24 & 14 & $4.13 * *$ \\
\hline Inferior-frontal gyrus & 30 & 46 & 10 & $4.06 * *$ \\
\hline \multirow[t]{3}{*}{ Supplementary motor area } & -4 & 6 & 44 & $3.69 *$ \\
\hline & -6 & 6 & 56 & $3.34^{*}$ \\
\hline & 10 & 6 & 50 & $3.27 *$ \\
\hline \multicolumn{5}{|l|}{ PD+HS > PD-HS on } \\
\hline \multirow[t]{3}{*}{ Superior parietal lobe } & -44 & -24 & 46 & $4.73 * *$ \\
\hline & -50 & -30 & 50 & $4.34 * *$ \\
\hline & -46 & -38 & 52 & $3.81 * *$ \\
\hline \multirow[t]{3}{*}{ Pre-supplementary motor area (pre-SMA) } & -12 & 10 & 40 & $4.21 * *$ \\
\hline & 6 & 20 & 56 & $3.81 * *$ \\
\hline & -24 & 14 & 62 & $3.59^{*}$ \\
\hline
\end{tabular}

Tests and anatomical structures for the successful (stop-inhibit) vs unsuccessful (failed) stop trials contrast in the erotic condition. $p<.05$

FWE cluster-wise corrected; $* p<.005 ; * * p<.001$. 
medRxiv preprint doi: https://doi.org/10.1101/2022.01.25.22269798; this version posted January $25,2022$. The copyright holder for this preprint (which was not certified by peer review) is the author/funder, who has granted medRxiv a license to display the preprint in It is made available under a perpetuity.

Hypersexuality alters cognitive control

Table S4. Stop fail in Erotic vs. Non-erotic trials.

Tests \& Anatomical structures

Medication x Group

Superior parietal lobe

Premotor area (BA6)

Supplementary motor area (Pre-SMA; BA6)

Superior frontal gyrus (BA6)

PD+HS on $>$ off

Caudate

\section{PD+HS > PD-HS on}

Superior parietal lobe (BA31)

Caudate

$\begin{array}{llll}X & Y & Z & \text { T-value }\end{array}$

$\begin{array}{cccc}-44 & -28 & 46 & 4.27^{* *} \\ -36 & -12 & 64 & 3.85^{*} \\ 0 & -6 & 68 & 3.31^{*} \\ -16 & 2 & 68 & 3.26^{*}\end{array}$

$\begin{array}{cccc}-4 & 8 & 8 & 4.16^{* \wedge} \\ -4 & 6 & 18 & 3.51^{* \wedge} \\ -12 & 2 & 14 & 3.18^{* \wedge}\end{array}$

$\begin{array}{llll}-52 & -20 & 52 & 4.11 * *\end{array}$

$\begin{array}{llll}-10 & -4 & 20 & 3.92 *\end{array}$

$\begin{array}{llll}-10 & 8 & 14 & 3.65 *\end{array}$

$\begin{array}{llll}-4 & 10 & 6 & 3.56 *\end{array}$

Tests and anatomical structures for unsuccessful stop (stop-fail) in erotic vs. non-erotic trials. $p<.05$ FWE cluster-wise corrected; $* p<.005 ; * * p<.001$ 
medRxiv preprint doi: https://doi.org/10.1101/2022.01.25.22269798; this version posted January 25, 2022. The copyright holder for this preprint (which was not certified by peer review) is the author/funder, who has granted medRxiv a license to display the preprint in It is made available under a perpetuity.

perpetuity. 4.0 International license

Hypersexuality alters cognitive control

Table S5. Behavioral results of the stop signal task (study 2) after real and sham intermittent theta burst stimulation.

\begin{tabular}{|c|c|c|c|c|c|c|}
\hline & $\begin{array}{c}\text { Real } \\
\text { Erotic }\end{array}$ & $\begin{array}{l}\text { Sham } \\
\text { Erotic }\end{array}$ & $p$-value & $\begin{array}{c}\text { Real } \\
\text { Non-erotic }\end{array}$ & $\begin{array}{c}\text { Sham } \\
\text { Non-erotic }\end{array}$ & $p$-value \\
\hline Go RT ${ }^{\mathrm{a}}(\mathrm{ms})$ & $564.82 \pm 106.38$ & $593.96 \pm 115.52$ & .06 & $552.00 \pm 93.11$ & $581.68 \pm 105.52$ & .05 \\
\hline $\begin{array}{l}\text { StopRespond } \\
\mathrm{RT}^{\mathrm{a}}(\mathrm{ms})\end{array}$ & $213.05 \pm 90.92$ & $242.50 \pm 106.40$ & .11 & $222.71 \pm 109.09$ & $221.95 \pm 106.88$ & .96 \\
\hline $\mathrm{p}$ (stop) $\%^{\mathrm{b}}$ & $71.37 \pm 14.56$ & $70.50 \pm 19.11$ & .72 & $71.17 \pm 13.78$ & $71.20 \pm 17.70$ & .99 \\
\hline $\mathrm{SSD}^{\mathrm{c}}(\mathrm{ms})$ & $304.99 \pm 128.79$ & $303.31 \pm 137.56$ & .89 & $297.72 \pm 118.86$ & $307.27 \pm 136.37$ & .47 \\
\hline SSRT (ms) & $341.51 \pm 138.42$ & $392.47 \pm 155.06$ & .02 & $352.12 \pm 182.19$ & $398.13 \pm 204.05$ & .04 \\
\hline ZRFT (ms) & $-0.56 \pm 0.54$ & $-0.56 \pm 0.63$ & .98 & $-0.58 \pm 0.66$ & $-0.63 \pm 0.69$ & .59 \\
\hline $\begin{array}{l}\text { Discrimination } \\
\text { errors (total) }\end{array}$ & $2.89 \pm 3.53$ & $2.50 \pm 3.24$ & .62 & $3.33 \pm 4.46$ & $2.83 \pm 3.93$ & .61 \\
\hline
\end{tabular}

Comparisons of task measures between real and sham sessions for erotic and non-erotic trials ( $p$ value: paired t-tests). ${ }^{\mathrm{a} R T}=$ reaction time; ${ }^{b} p($ stop $) \%=\%$ probability of stopping; ${ }^{c} S S D=$ Stop Signal Delay; ${ }^{d} S S R T$ : Stop Signal Reaction Time; ${ }^{e} Z R F T$ : Z-score Relative Finish Time. 
medRxiv preprint doi: https://doi.org/10.1101/2022.01.25.22269798; this version posted January 25, 2022. The copyright holder for this preprint (which was not certified by peer review) is the author/funder, who has granted medRxiv a license to display the preprint in

It is made available under a CC-BY-NC-ND 4.0 International license .

Hypersexuality alters cognitive control

\section{Supplementary Figures}

Figure S1. Structure of the 13 DCMs tested and selection of most likely model.

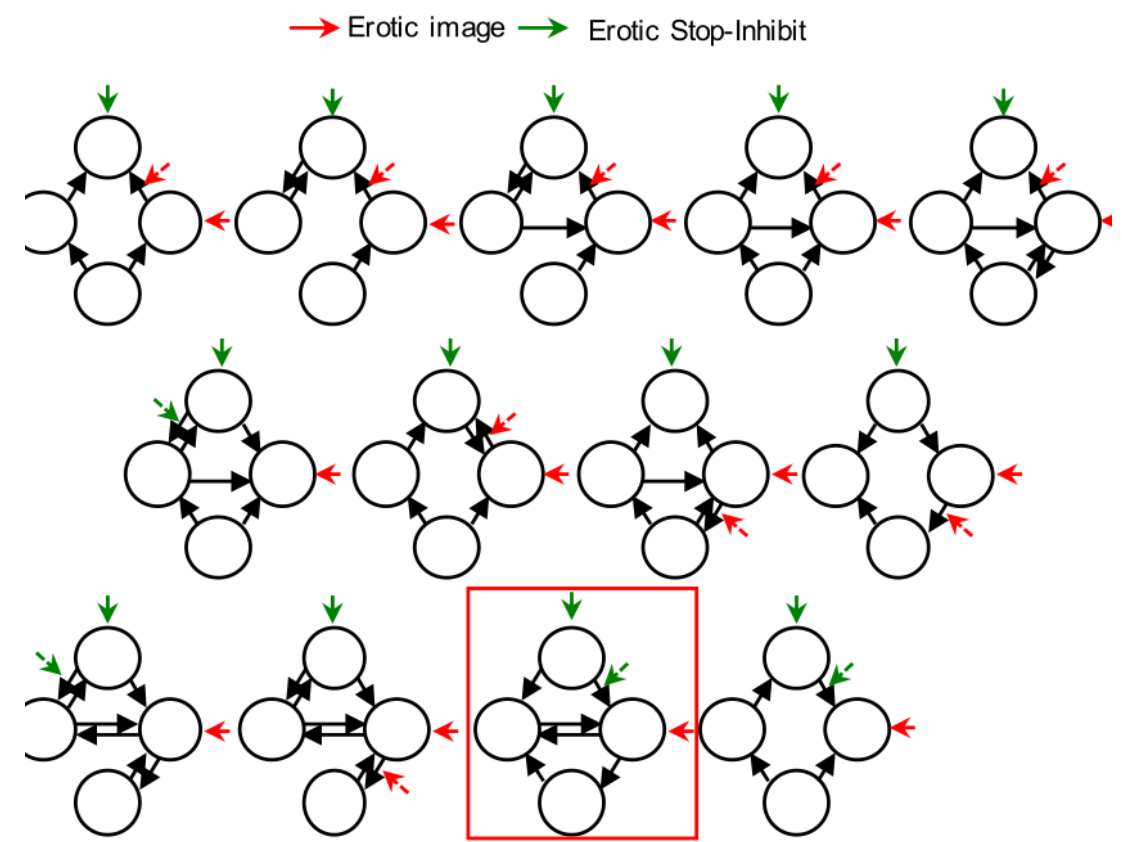

The 13 generative models represent alternative hypotheses of cortico-subcortical interactions during cognitive control while exposed to sexual cues in hypersexuality. The most likely model after BMS is highlighted in red square.

Figure S2. Bayesian factor sequential analysis for SSRT.

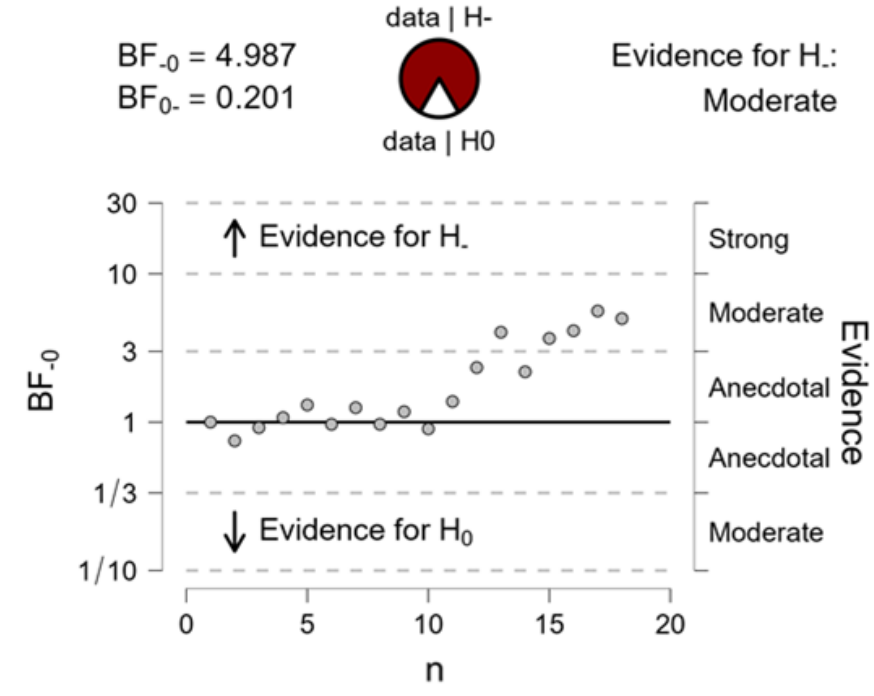

Study 1 (PD+HS on < off). 
medRxiv preprint doi: https://doi.org/10.1101/2022.01.25.22269798; this version posted January 25, 2022. The copyright holder for this preprint (which was not certified by peer review) is the author/funder, who has granted medRxiv a license to display the preprint in It is made available under a CC-BY-NC.

perpetuity. 4.0 International license.

Hypersexuality alters cognitive control

\section{Figure S3. StopInhibit vs. StopFail activity maps.}
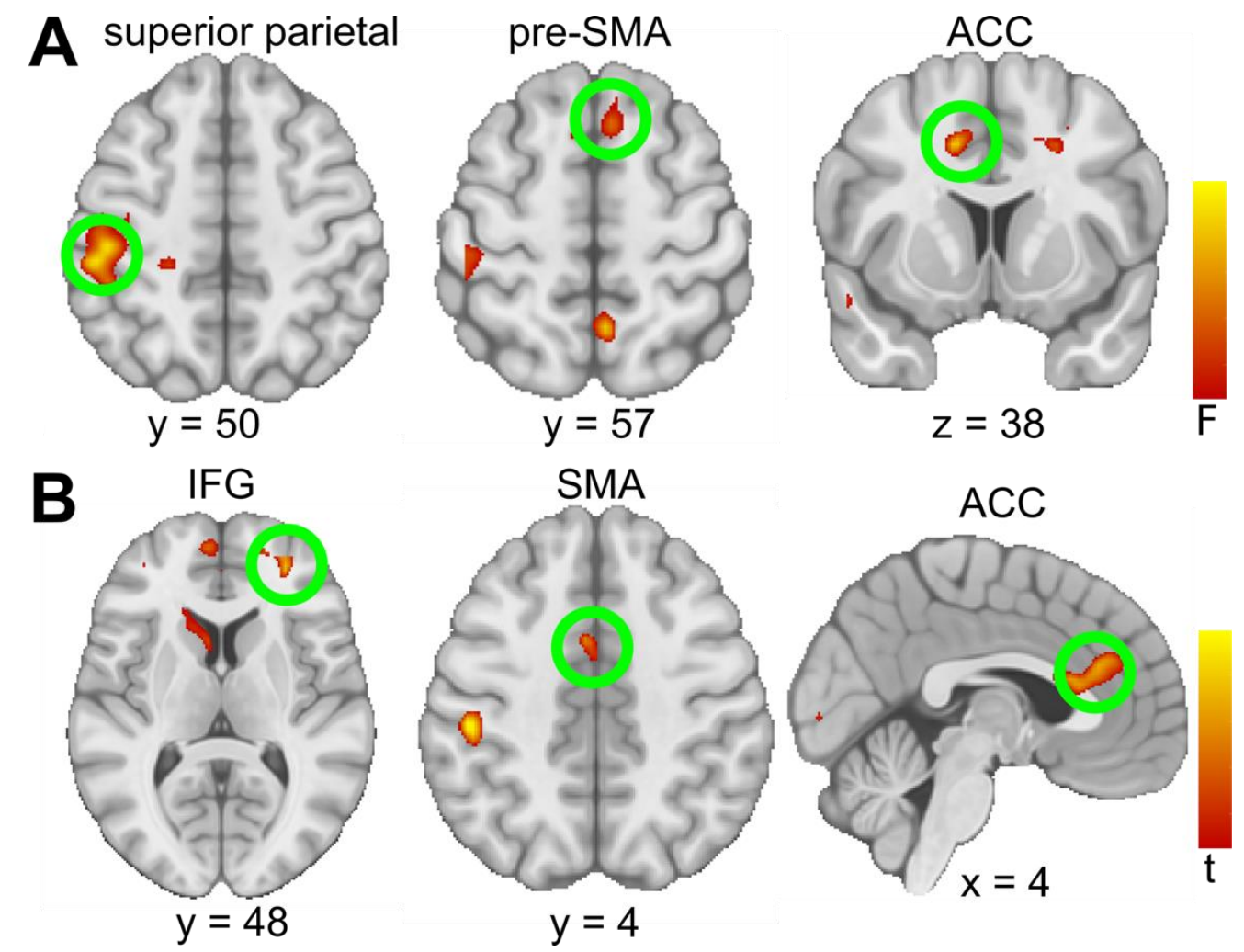

(A) Main effect of medication and (B) activity driven by PD+HS patients (on vs off medication). IFG = Inferior-frontal gyrus.

Figure S4. Tracts representation and DTI scalar measures (FA, MD*) for controls.

A
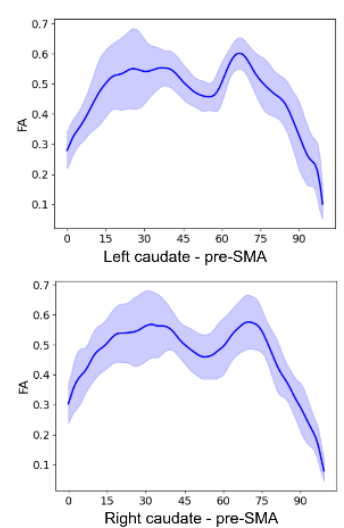
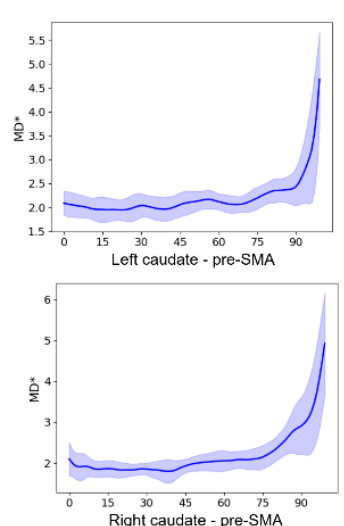
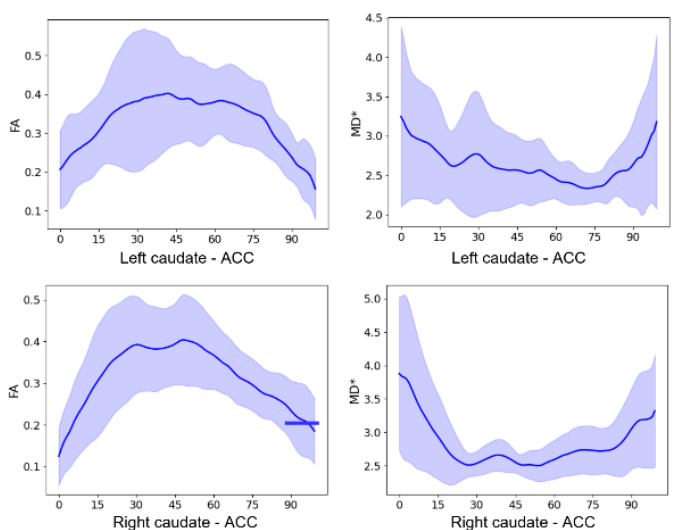

(A) Fractional anisotropy (FA) and mean diffusivity (MD) along the segments of right-left caudate and pre-SMA tracts and (B), along the segments of right-left caudate and anterior cingulate cortex tracts. 
medRxiv preprint doi: https://doi.org/10.1101/2022.01.25.22269798; this version posted January 25, 2022. The copyright holder for this preprint (which was not certified by peer review) is the author/funder, who has granted medRxiv a license to display the preprint in It is made available under a CC-BY-NC.

CC-BY-NC-ND 4.0 International license.

Hypersexuality alters cognitive control

Figure S5. Correlation between diffusion tensor imaging (DTI) scalar measures fractional anisotropy $(F A)$, mean diffusivity $\left(M D^{*}\right)$ - and SSRT.
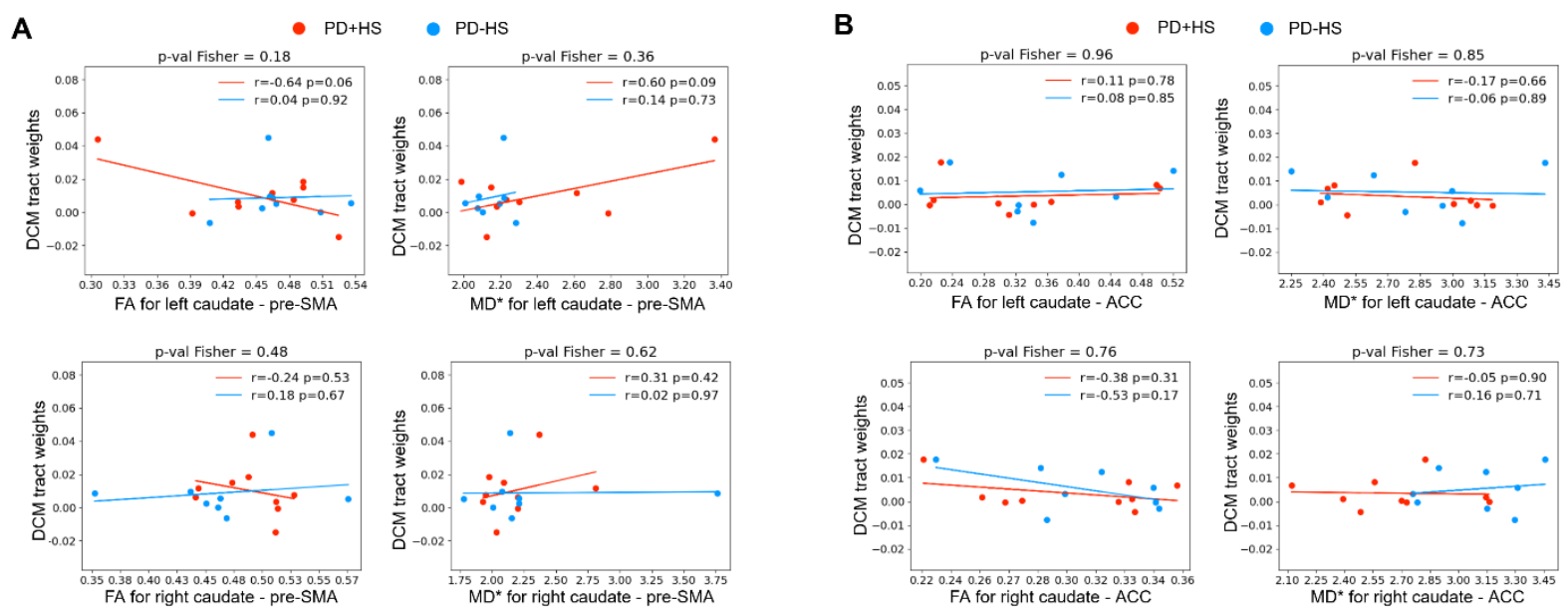

Comparisons included PD+HS ( $\mathrm{n}=10)$ and PD-HS patients ( $\mathrm{n}=14)$. (A) Correlation between FA and SSRT; (B) Correlation between MD* and SSRT (MD* is also called trace or TR, which is MD*3).

\section{Figure S6. Correlation between DTI scalar measures (FA, MD*) and DCM parameters.}

A
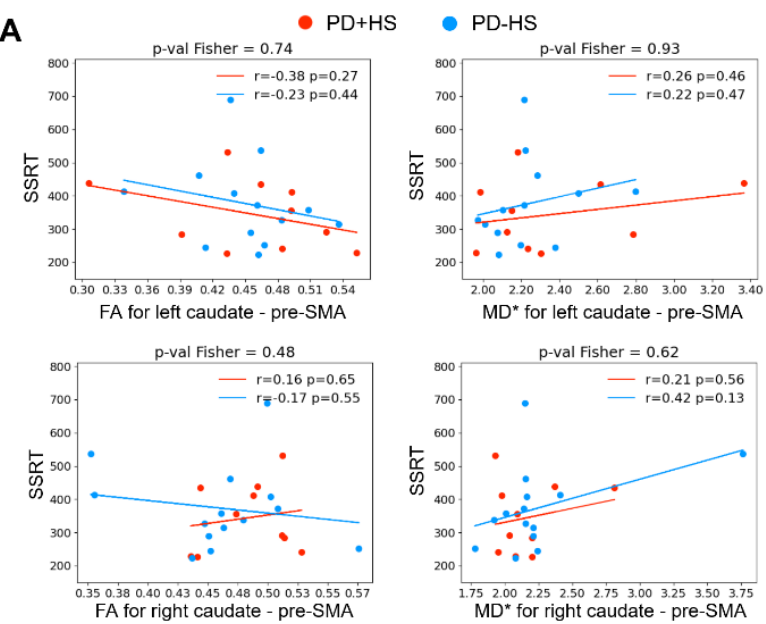

B
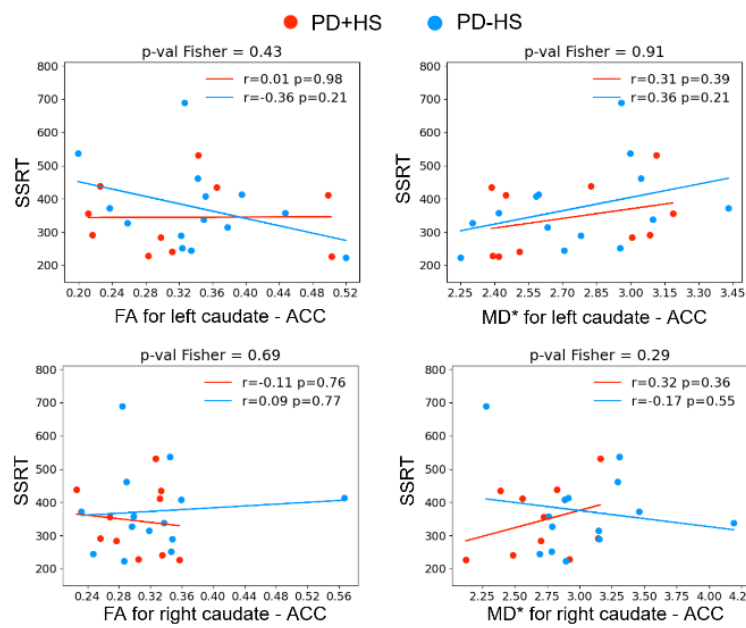

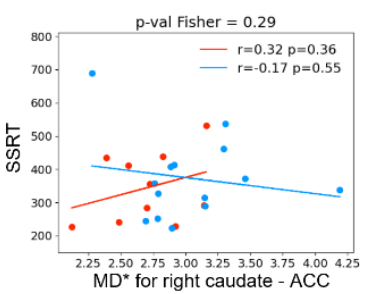

Comparisons included PD+HS (n=9) and PD-HS patients (n=8). (A) Correlation between FA and DCM parameters; (B)

Correlation between MD* and DCM parameters (MD* is also called trace or TR, which is MD*3). 
medRxiv preprint doi: https://doi.org/10.1101/2022.01.25.22269798; this version posted January 25, 2022. The copyright holder for this preprint (which was not certified by peer review) is the author/funder, who has granted medRxiv a license to display the preprint in It is made available under perpetuity.

perpetuity.
CC-BY-NC-ND 4.0 International license .

Hypersexuality alters cognitive control

\section{Figure S7. Bayesian factor sequential analysis for SSRT.}
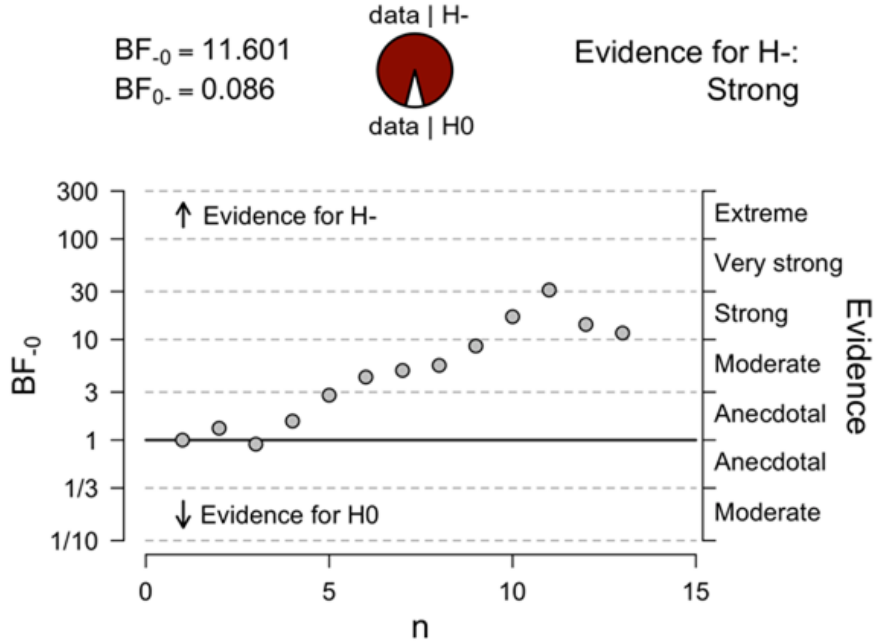

Study 2 (real < sham). 